\title{
Characterization of single-stranded DNA-binding proteins from the psychrophilic bacteria Desulfotalea psychrophila, Flavobacterium psychrophilum, Psychrobacter arcticus, Psychrobacter cryohalolentis, Psychromonas ingrahamii, Psychroflexus torquis, and Photobacterium profundum
}

\author{
Marta Nowak, Marcin Olszewski, Marta Śpibida and Józef Kur ${ }^{*}$
}

\begin{abstract}
Background: Single-stranded DNA-binding proteins (SSBs) play essential roles in DNA replication, recombination and repair in Bacteria, Archaea and Eukarya. In recent years, there has been an increasing interest in SSBS, since they find numerous applications in diverse molecular biology and analytical methods.

Results: We report the characterization of single-stranded DNA-binding proteins from the psychrophilic bacteria Desulfotalea psychrophila (DpsSSB), Flavobacterium psychrophilum (FpsSSB), Psychrobacter arcticus (ParSSB), Psychrobacter cryohalolentis (PcrSSB), Psychromonas ingrahamii (PinSSB), Photobacterium profundum (PprSSB), and Psychroflexus torquis (PtoSSB). The proteins show a high differential within the molecular mass of their monomers and the length of their amino acid sequences. The high level of identity and similarity in respect to the ECOSSB is related to the OB-fold and some of the last amino acid residues. They are functional as homotetramers, with each monomer encoding one single stranded DNA binding domain (OB-fold). The fluorescence titrations indicated that the length of the ssDNA-binding site size is approximately $30 \pm 2$ nucleotides for the PinSSB, $31 \pm 2$ nucleotides for the DpsSSB, and $32 \pm 2$ nucleotides for the ParSSB, PcrSSB, PprSSB and PtoSSB. They also demonstrated that it is salt independent. However, when the ionic strength was changed from low salt to high, binding-mode transition was observed for the FpsSSB, at $31 \pm 2$ nucleotides and $45 \pm 2$ nucleotides, respectively. As expected, the SSB proteins under study cause duplex DNA destabilization. The greatest decrease in duplex DNA melting temperature was observed in the presence of the PtoSSB $17^{\circ} \mathrm{C}$. The SSBs in question possess relatively high thermostability for proteins derived from cold-adapted bacteria.

Conclusion: The results showed that SSB proteins from psychrophilic microorganisms are typical bacterial SSBs and possess relatively high thermostability, offering an attractive alternative to other thermostable SSBs in molecular biology applications.
\end{abstract}

Keywords: DNA replication, Expression, Psychrophilic microorganism, SSB, Thermostability, Psychrophiles

\footnotetext{
*Correspondence: kur@pg.gda.pl

Department of Microbiology, Faculty of Chemistry, Gdańsk University of

Technology, ul. Narutowicza 11/12, 80-233 Gdańsk, Poland
} 


\section{Background}

Single-stranded DNA-binding proteins (SSBs) are indispensable elements in the cells of all living organisms. They interact with ssDNA regardless of sequence, preventing them from forming secondary structures and protecting them from degradation by nucleases [1]. In this way, they participate in all the processes involving ssDNA, such as replication, repair and recombination [2-5]. Although there are differences in amino acid sequences, SSBs have a high-conservative domain, the oligonucleotide/oligosaccharide-binding fold, referred to as the OB-fold, which is responsible for binding with ssDNA [6]. In the single-stranded DNA-binding proteins described so far, four OB-fold domains form an active protein. These proteins also have the ability to bind RNA and are present in all three branches of live organisms and in viruses. The cooperative binding of single-strand DNA and RNA, which is a property of SSBs, has led to their being used as tools in molecular biology methods and analytics. Thermostable proteins are particularly useful in this respect. To date, only a few thermostable SSB proteins with these valuable applications have been identified.

Information resources on proteins from cold-adapted microorganisms are extremely limited, particularly when the spread of psychrophilic organisms in the environment is taken into account; approximately $85 \%$ of the Earth's Biosphere is an environment with temperatures of below $5^{\circ} \mathrm{C}$.

We recently presented a study on the production, purification and molecular characteristics of a singlestranded DNA binding protein from Pseudoalteromonas haloplanktis, the first report of a protein of this kind from a psychrophilic microorganism [7]. The proteins which are the focus of interest in this article come from different phylogenetically-related obligate and facultative psychrophilic Gram-negative bacteria. Photobacterium profundum str. SS9, which belongs to Gammaproteobacteria, Vibrionaceae family, was isolated from the Sulu Trough associated with Amphipoda at a depth of $2551 \mathrm{~m}$. It is a psychrophilic and moderately barophilic bacterium with an optimum growth temperature and pressure of $15^{\circ} \mathrm{C}$ and $20 \mathrm{MPa}$, respectively [8]. P. profundum SS9 is a genetically tractable model system for studies of low-temperature and highpressure adaptation [9]. Desulfotalea psychrophila, which belongs to Deltaproteobacteria, Desulfobulbaceae family, is a sulfate-reducing bacteria isolated from permanently cold Arctic sediments off the coast of Svalbard, Norway [10]. Flavobacterium psychrophilum, belongs to Bacteroidetes, Flavobacteriaceae family, is a facultative psychrophilic bacterium and one of the most serious of the fish pathogens [11]. The Psychrobacter arcticus and Psychrobacter cryohalolentis strains, which belong to Gammaproteobacteria, Moraxellaceae family, were isolated from permafrost samples taken from the Kolyma lowland region of Siberia, Russia [12]. P. arcticus was a model organism for studies on the mechanisms of adaptation to low temperatures [13]. Psychromonas ingrahamii bacterium, which belongs to Gammaproteobacteria, Psychromonadaceae family, was isolated from a sea ice core collected on Point Barrow in Alaska, USA. The bacterium grows well at $\mathrm{NaCl}$ concentrations of $1-10 \%$ and at temperatures of -12 to $10^{\circ} \mathrm{C}$; no growth is observed at $15^{\circ} \mathrm{C}$, and the optimal growth temperature is $5^{\circ} \mathrm{C}$. Psychromonas ingrahamii is the only bacterium growing at such a low temperature to have been described to date [14]. Psychroflexus torquis, which belongs to Bacteroidetes, Flavobacteriaceae family, is isolated from Antarctic sea ice psychrophilic bacterium. The representatives of this species possess an uncommon characteristic, the ability to synthesize polyunsaturated fatty acids [15].

The aim of this study was to clone and overexpress $D$. psychrophila, F. psychrophilum, $P$. arcticus, P. cryohalolentis, $P$. ingrahamii, $P$. profundum, and $P$. torquis ssb-like genes in E. coli, purify the gene products and study their biochemical properties.

\section{Results}

\section{Sequence analysis}

The sequence analysis of the D. psychrophila (GenBank accession No. NC_006138; [16]), F. psychrophilum (GenBank accession No. NC_009613; [17]), P. arcticus (GenBank accession No. NC_007204; [18]), P. cryohalolentis (GenBank accession No. NC_007969; Gene Bank Project: PRJNA58373), P. ingrahamii (GenBank accession No. NC_008709; [19]), P. profundum (GenBank accession No. NC_006370; [20]) and P. torquis (GenBank accession No. NC_018721; [15]) genomes indicated the presence of a single $s s b$ gene. In the case of $F$. psychrophilum, $P$. ingrahamii and $P$. torquis, there were additional genes possessing sequences similar to the ssDNA binding domain. The product of the additional gene from $F$. psychrophilum was a protein of unknown function, while that from $P$. ingrahamii was the PriB. In P. torquis, it was a short (102 aa), single-stranded DNA binding protein without a characteristic sequence of last amino acid residues, in view of which, we omitted that protein from our research. On the basis of the $s s b$ gene organization and the number of $s s b$ genes paralogs, bacteria have been classified in four different groups [21]. P. arcticus, P. cryohalolentis and $P$. profundum are classified as group III, which contains bacteria with $s s b$ gene organization $u v r A-s s b$, whereas D. psychrophila, F. psychrophilum, P. ingrahamii, and $P$. torquis are classified as group IV, which contains bacteria with $s s b$ placed neither between $r p s F$ and $r p s R$ nor divergently located to $u v r A$.

The DpsSSB, FpsSSB, ParSSB, PcrSSB, PinSSB, PprSSB, and PtoSSB proteins contain 142, 140, 213, 219, 222, 183, and 151 amino acid residues, respectively, including the 
$\mathrm{N}$-terminal methionine, as is apparent from the nucleotide sequence. Analysis of the primary structures by RPSBLAST revealed the presence of two distinctive regions in the proteins in question: one putative OB-fold domain, from amino acid 1 to $105-110$, and one C-terminal domain, which contains four conserved terminal amino acid residues common in all known bacterial SSB proteins. The molecular mass of its monomers show a high differential, ranging from 15.6 to $25.1 \mathrm{kDa}$. Besides the OB-fold, the C-terminal fragment has the characteristic of a highly differential length, ranging from 31 to 112 amino acid residues. At their ends, the C-terminal domains have amino acids which are either similar or identical to the EcoSSB. The computable isoelectric point in these proteins has values in the range of 5-6, which is typical for SSBs with the exception of PinSSB, pI 7.79 (Table 1).

Figure 1 shows the multiple amino acid alignment of the SSB proteins from the psychrophilic bacteria under study, from Shewanella woodyi (GenBank accession No. NC_010506; [22]), mesophilic E. coli (GenBank Accession No. NC_007779; [23]) and Bacillus subtilis (GenBank Accession No. NC_000964; [24]), and from the thermophilic Thermoanerobacter tengcongensis (GenBank Accession No. NC_003869; [25]) and Thermotoga maritima (GenBank Accession No. NC_000853; [26]) microorganisms. The protein sequences of the proteins under scrutiny share a $26-70 \%$ identity and a $46-75 \%$ similarity with the E. coli K12 SSB, a 21-53\% identity and 38-66\% similarity with the Shewanella woodyi SSB, a $21-31 \%$ identity and $37-48 \%$ similarity with the $B$. subtilis SSB, a $21-36 \%$ identity and $36-53 \%$ similarity with the Thermoanaerobacter tengcongensis SSB3, and a 19-31\% identity and 34-52\% similarity with the Thermotoga maritima (Table 2). The similarity between these proteins refers primarily to the $\mathrm{N}$-terminal domain and the four or five terminal amino acids of $\mathrm{C}$ terminal domain which are common in all the known bacterial SSB proteins.

The C-terminal domain of bacterial SSBs contains a high number of negatively charged amino acid residues, which are required for the interaction with other proteins but are not essential to DNA binding. In the C-terminal domains of proteins under analysis in this study, the content of negatively charged residues is similar to, or even higher than, that found in the EcoSSB.

The EcoSSB base-stacking residues are Trp-40, Trp-54, Phe-60, and Trp-88. In contrast to the TmaSSB or TteSSB3, the location of these residues is precisely preserved in the PinSSB and PprSSB. In the FpsSSB and PtoSSB, this location is shifted with one amino acid residue, and instead of tryptophan, they have a tyrosine at position 39, and arginine residues rather than phenylalanine residue at position 59. The displacement of two amino acid residues is observed in the ParSSB and PcrSSB, where the $86^{\text {th }}$ position is occupied by tyrosine and not by tryptophan. In the DpsSSB, the location of the base-stacking residues is shifted with four residues, namely Trp-36, and then with five; Trp-49, Trp-55, Trp-83, while tryptophan replaces phenylalanine in the $55^{\text {th }}$ position. With the exception of arginine, the amino acids residues thus replaced are also aromatic and, in participating in ssDNA binding, can play an analogous role to those residues in the EcoSSB. Highly conserved His-55, Gln-76 and Gln-110 residues, important for the homotetramerization of the EcoSSB, are present in the PprSSB protein. In the other proteins under study, only histidine residues were found, at the $55^{\text {th }}$ position in the $\operatorname{PinSSB}$, the $54^{\text {th }}$ position in the FpsSSB and PtoSSB, the $54^{\text {th }}$ position in the ParSSB and $P c r S S B$, and the $50^{\text {th }}$ position in the DpsSSB.

\section{Oligomerization status}

In chemical cross-linking experiments using glutaraldehyde, the DpsSSB, FpsSSB and PtoSSB complexes were found at a position corresponding to a molecular mass of approximately $80 \mathrm{kDa}$, the PprSSB complexes were found at a position corresponding to a molecular mass of about $100 \mathrm{kDa}$, the ParSSB and PcrSSB complexes were found at a position corresponding to a molecular mass of around $116 \mathrm{kDa}$, and the PinSSB complexes were found at a position corresponding to a molecular mass of approximately $140 \mathrm{kDa}$ (Figure 2A). We observed that the psychrophilic SSB proteins in question have anomalous mobility in

Table 1 Characteristics resulting from the amino acid sequence analysis of the SSB proteins under study

\begin{tabular}{|c|c|c|c|c|c|c|c|}
\hline SSB & $\begin{array}{c}\text { Size of } \\
\text { monomer [kDa] }\end{array}$ & $\begin{array}{l}\text { Length of } \\
\text { sequence [aa] }\end{array}$ & $\begin{array}{l}\text { Length of C-terminal } \\
\text { domain [aa] }\end{array}$ & $\begin{array}{l}\text { Sequence of last important } \\
\text { amino acid residues }\end{array}$ & pl & $\begin{array}{l}\text { Aliphatic } \\
\text { index }\end{array}$ & $\begin{array}{l}\text { No. of Cys } \\
\text { residues }\end{array}$ \\
\hline DpsSSB & 15.6 & 142 & 37 & DVPF & 5.46 & 61.20 & 1 \\
\hline FpsSSB & 15.9 & 140 & 31 & DLPF & 5.94 & 73.07 & 2 \\
\hline ParSSB & 22.8 & 213 & 105 & DIPF & 5.91 & 49.11 & 0 \\
\hline PCrSSB & 23.3 & 219 & 111 & DIPF & 5.70 & 43.29 & 0 \\
\hline PinSSB & 25.1 & 222 & 112 & DIPF & 7.79 & 41.80 & 1 \\
\hline PtossB & 17.1 & 151 & 43 & DLPF & 5.67 & 61.32 & 3 \\
\hline PprSSB & 20.4 & 183 & 76 & DIPF & 5.43 & 54.37 & 0 \\
\hline EcossB & 18.9 & 178 & 73 & DIPF & 5.44 & 56.97 & 0 \\
\hline
\end{tabular}




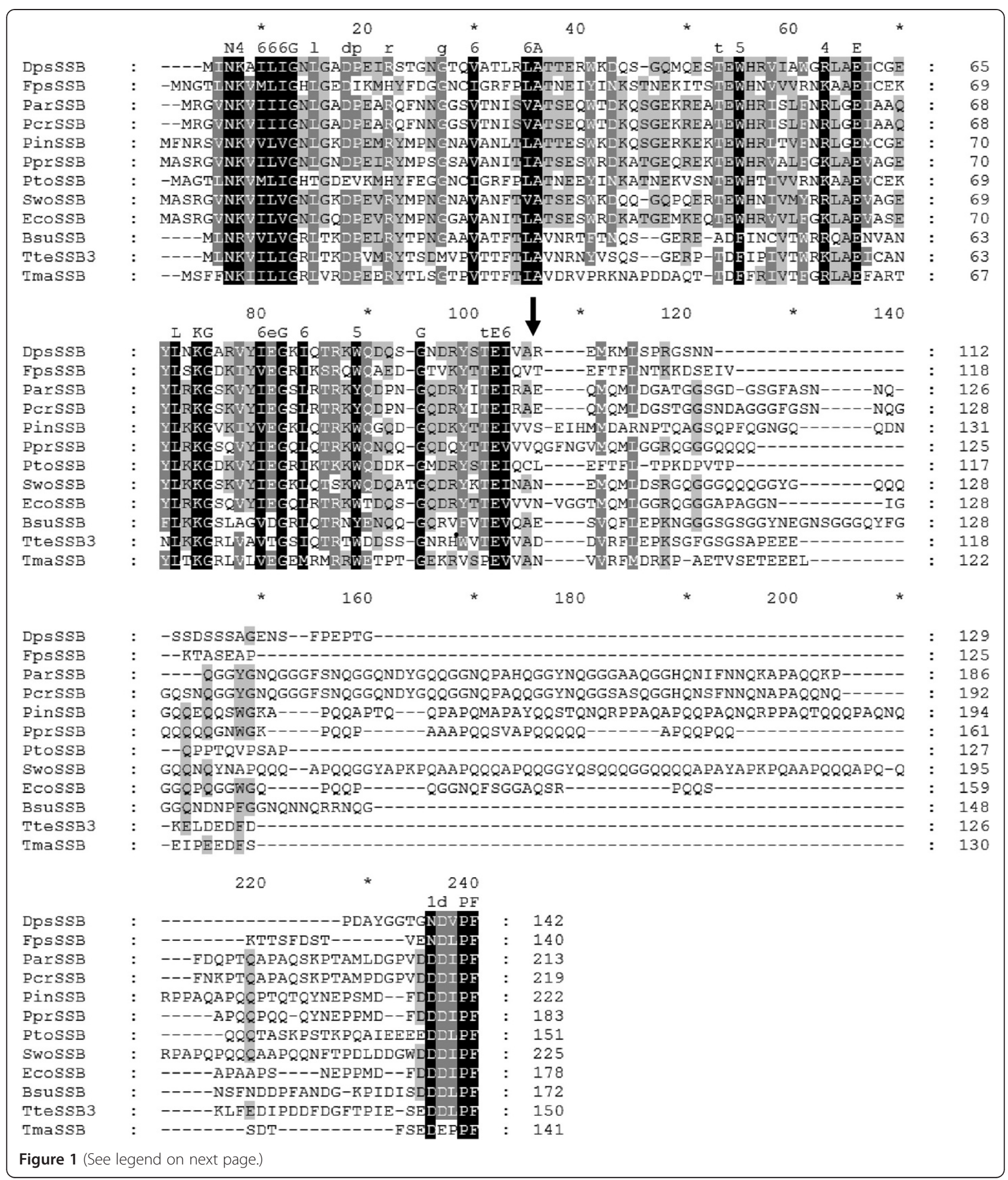


(See figure on previous page.)

Figure 1 The multiple amino acid alignment of the SSB proteins under study, with the SSBs from psychrophilic, mesophilic and thermophilic bacteria. The alignments were performed by dividing the amino acids into six similarity groups: group $1 \mathrm{~V}, \mathrm{~L}, \mathrm{l}, \mathrm{M}, \mathrm{group} 2 \mathrm{~W}, \mathrm{~F}, \mathrm{Y}$, group 3 E, D, group 4 K, R, group 5 Q, D, and group $6 \mathrm{~S}, \mathrm{~T}$. The capital letters represent single amino acid codes. White fonts on black boxes represent $100 \%$ similarity, white fonts on grey boxes denote $<80 \%$ similarity, and black fonts on grey boxes show <60\% similarity. Abbreviations: DpsSSB Desulfotalea psychrophila (NCBI Reference Sequence: WP_011189820.1), FpsSSB Flavobacterium psychrophilum (NCBI Reference Sequence: WP_011963776.1), ParSSB Psychrobacter arcticus (NCBI Reference Sequence: AAZ19531.1), PcrSSB Psychrobacter cryohalolentis (NCBI Reference Sequence: ABE75735.1), PinSSB Psychromonas ingrahamii (NCBI Reference Sequence: WP_011771629.1), PprSSB Photobacterium profundum (NCBI Reference Sequence: WP_011219846.1), PtoSSB Psychroflexus torquis (NCBI Reference Sequence: WP_015023871.1), SwoSSB Shewanella woodyi (NCBI Reference Sequence: WP_012323283.1), EcoSSB Escherichia coli K12 (NCBI Reference Sequence: YP_492202.1), BsuSSB Bacillus subtilis (NCBI Reference Sequence: NP_391970.1), TteSSB3 Thermoanerobacter tengcongensis MB4 (NCBI Reference Sequence: AAM25884.1), and TmaSSB Thermotoga maritima MSB8 (NCBI Reference Sequence: WP_004081225.1). An arrow indicates the boundary between the N-and C-terminal domains.

SDS-PAGE gels than would be expected on the basis of their predicted molecular masses. This phenomenon has also been observed in SSBs from Shewanella strains [27] and could be a characteristic feature of psychrophilic single-stranded DNA-binding proteins. The SSBs from $D$. psychrophila, F. psychrophilum and P. torquis were found at a position corresponding to a molecular mass of around $20 \mathrm{kDa}$ (Figure 2A), while their calculated molecular masses are 15.6, 15.9 and $17.1 \mathrm{kDa}$, respectively. The PprSSB was found at a position corresponding to a molecular mass of approximately $25 \mathrm{kDa}$, while its calculated molecular mass is $20.4 \mathrm{kDa}$ (Figure 2A). The ParSSB, PcrSSB and PinSSB were found at positions corresponding to molecular masses of around 25,27 and $32 \mathrm{kDa}$, although their predicted molecular masses are 22.8, 23.3 and $25.1 \mathrm{kDa}$, accordingly (Figure 2A). Taken together, these results confirmed our prediction that the DpsSSB, FpsSSB, ParSSB, PcrSSB, PinSSB, PprSSB and PtoSSB exist as homotetramers in solution.

The oligomerization status of the SSBs was also analyzed by centrifugation in 15 to $30 \%(w / v)$ glycerol gradients. To prevent nonspecific aggregation of the proteins during the experiments, $\mathrm{NaCl}$ at a final concentration of $0.5 \mathrm{M}$ was added to the solutions used for the gradients. The centrifugation in was carried out three times, and the same sedimentation behaviors were observed in all the independent tests. The sedimentation patterns of the SSB proteins in question, the PhaSSB, the EcoSSB and the standard proteins in the glycerol gradients suggest that all SSB proteins under study form homotetramers in the solution (Figure 2B).

An analytical gel filtration chromatography analysis of the purified psychrophilic SSBs revealed a single peak for each protein. As calculated using a regression curve equation, there was a peak with a molecular mass of $59 \mathrm{kDa}$ for the DpsSSB, $69.5 \mathrm{kDa}$ for the FpsSSB, 94.4 $\mathrm{kDa}$ for the ParSSB, $96.1 \mathrm{kDa}$ for the PcrSSB, 102.8 kDa for the PinSSB, 85.4 kDa for the PprSSB, and $72.3 \mathrm{kDa}$ for the PtoSSB, (Figure 2C). The native molecular mass of each peak represents 3.8 for the DpsSSB mass monomer, 4.4 for the FpsSSB mass monomer, 4.1 for the ParSSB, PcrSSB and PinSSB mass monomers, and 4.2 for the PprSSB and PtoSSB mass monomers, respectively. Psychrophilic single-stranded DNA binding proteins therefore exist in solution as homotetramers.

\section{ssDNA binding properties}

The purified SSB proteins were analyzed for singlestranded DNA binding activity. In these experiments, a fixed concentration of $(\mathrm{dT})_{\mathrm{n}}(\mathrm{n}=35,76$ or 120

Table 2 Identity and similarity of the SSB proteins under study to the EcoSSB, SwoSSB, BsuSSB, TteSSB3, and TmaSSB

\begin{tabular}{|c|c|c|c|c|c|c|c|}
\hline SSB & DpsSSB & FpsSSB & ParSSB & PcrSSB & PinSSB & PprSSB & PtoSSB \\
\hline Identity to EcoSSB & $41 \%$ & $26 \%$ & $49 \%$ & $45 \%$ & $45 \%$ & $70 \%$ & $33 \%$ \\
\hline Similarity to EcoSSB & $56 \%$ & $46 \%$ & $57 \%$ & $56 \%$ & $58 \%$ & $75 \%$ & $49 \%$ \\
\hline Identity to SwOSSB & $34 \%$ & $21 \%$ & $47 \%$ & $46 \%$ & $53 \%$ & $53 \%$ & $30 \%$ \\
\hline Similarity to SwOSSB & $42 \%$ & $38 \%$ & $55 \%$ & $55 \%$ & $66 \%$ & $63 \%$ & $42 \%$ \\
\hline Identity to BsuSSB & $28 \%$ & $21 \%$ & $31 \%$ & $31 \%$ & $28 \%$ & $30 \%$ & $21 \%$ \\
\hline Similarity to BsuSSB & $46 \%$ & $37 \%$ & $47 \%$ & $47 \%$ & $40 \%$ & $48 \%$ & $38 \%$ \\
\hline Identity to TtesSB3 & $36 \%$ & $29 \%$ & $23 \%$ & $22 \%$ & $21 \%$ & $22 \%$ & $29 \%$ \\
\hline Similarity to TteSSB3 & $53 \%$ & $42 \%$ & $39 \%$ & $39 \%$ & $36 \%$ & $40 \%$ & $41 \%$ \\
\hline Identity to TmaSSB & $31 \%$ & $25 \%$ & $20 \%$ & $21 \%$ & $19 \%$ & $25 \%$ & $23 \%$ \\
\hline Similarity to TmaSSB & $52 \%$ & $46 \%$ & $34 \%$ & $34 \%$ & $34 \%$ & $43 \%$ & $41 \%$ \\
\hline
\end{tabular}




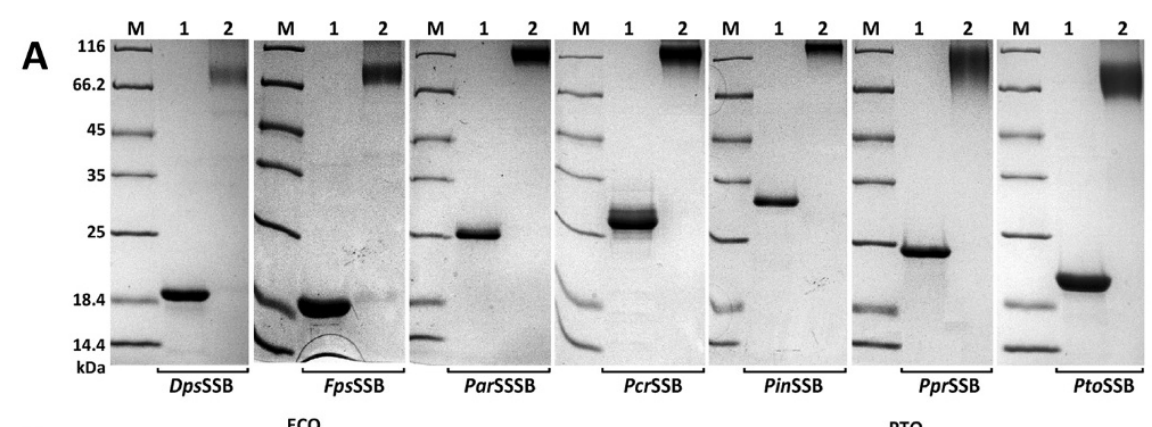

B

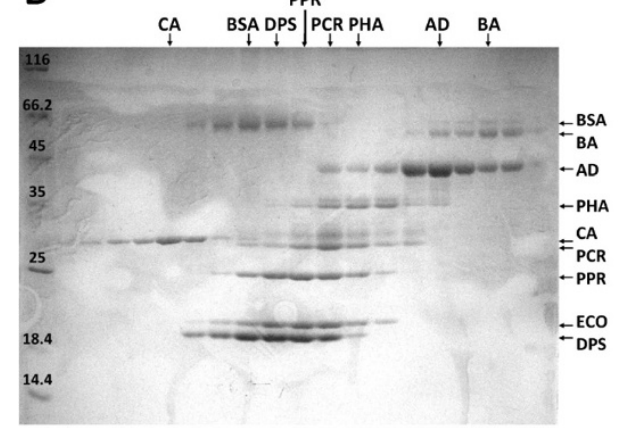

PTO

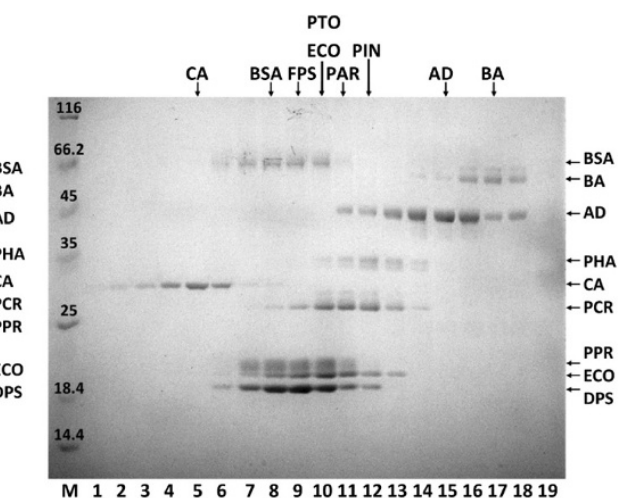

C

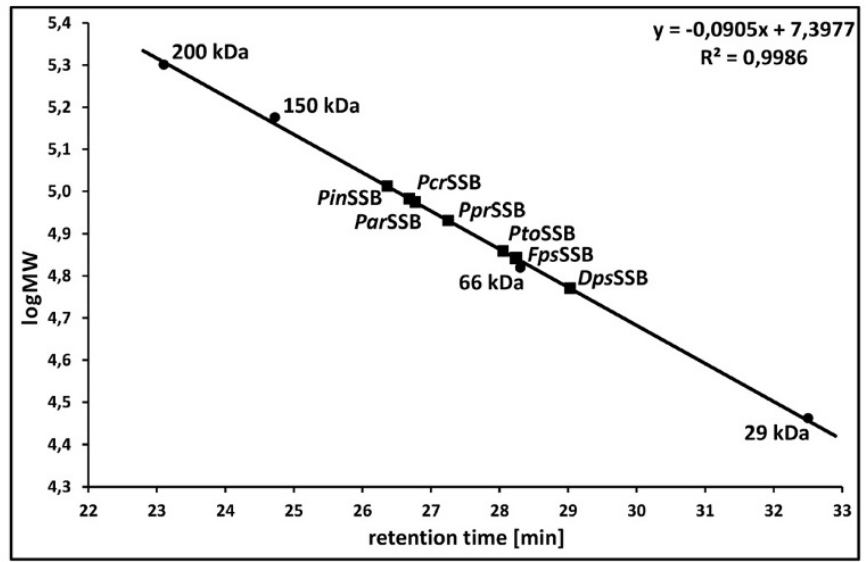

Figure 2 Results of chemical cross-linking, ultracentrifugation and gel filtration experiments of SSB proteins. A: The results of chemical cross-linking experiments using $0.5 \%(\mathrm{~V} / \mathrm{V})$ glutaraldehyde with the SSB proteins under study, for $15 \mathrm{~min}$ at $25^{\circ} \mathrm{C}$ (lanes 2) and non-cross-linked samples (lanes 1). The fractions were analyzed by SDS-PAGE. B: Sedimentation analysis of the psychrophilic SSB proteins, PhaSSB, EcoSSB and standard proteins. $50 \mu \mathrm{l}$ of $300 \mu \mathrm{M}$ SSBs and standard proteins were centrifuged in linear 15 to $30 \%(\mathrm{w} / \mathrm{v})$ glycerol gradients, as described in the Methods section. Lane M: Unstained Protein Weight Marker (Fermentas, Lithuania), with the molecular mass of proteins marked. Lane 1-19: fraction number. The fractions with proteins were analyzed by SDS-PAGE. The fractions at which the maximal amount of protein appears are shown by arrows. The standard proteins used are CA, carbonic anhydrase (29 kDa); BSA, bovine serum albumin (66 kDa); AD, alcohol dehydrogenase $(150 \mathrm{kDa})$, and BA, $\beta$-amylase (200 kDa). C: Analytical gel filtration of the psychrophilic SSB proteins under study. A standard linear regression curve is shown. It was generated by plotting the log of the molecular mass of the calibration proteins against their retention times [min]. The calibration proteins include $\beta$-amylase (200 kDa), alcohol dehydrogenase (150 kDa), bovine albumin (66 kDa) and carbonic anhydrase (29 kDa).

nucleotides in length) were incubated with various SSB concentrations and the resulting complexes were analyzed by agarose gel electrophoresis (Figure 3 ). When $\mathrm{dT}_{35}$ was incubated with increasing concentrations of each of the SSB proteins, a single band of reduced mobility was observed and remained constant even at a higher protein concentration (complex I). A band with the same mobility was observed for $(\mathrm{dT})_{76}$ at a low protein concentration, but a second band with a lower mobility was observed at a high protein concentration (complex II). When SSB: $\mathrm{dT}_{120}$ complexes were analyzed, a third band with a lower mobility was detected (complex III). This implies that the length of ssDNA required for efficient protein binding is less than 35 nucleotides long. 


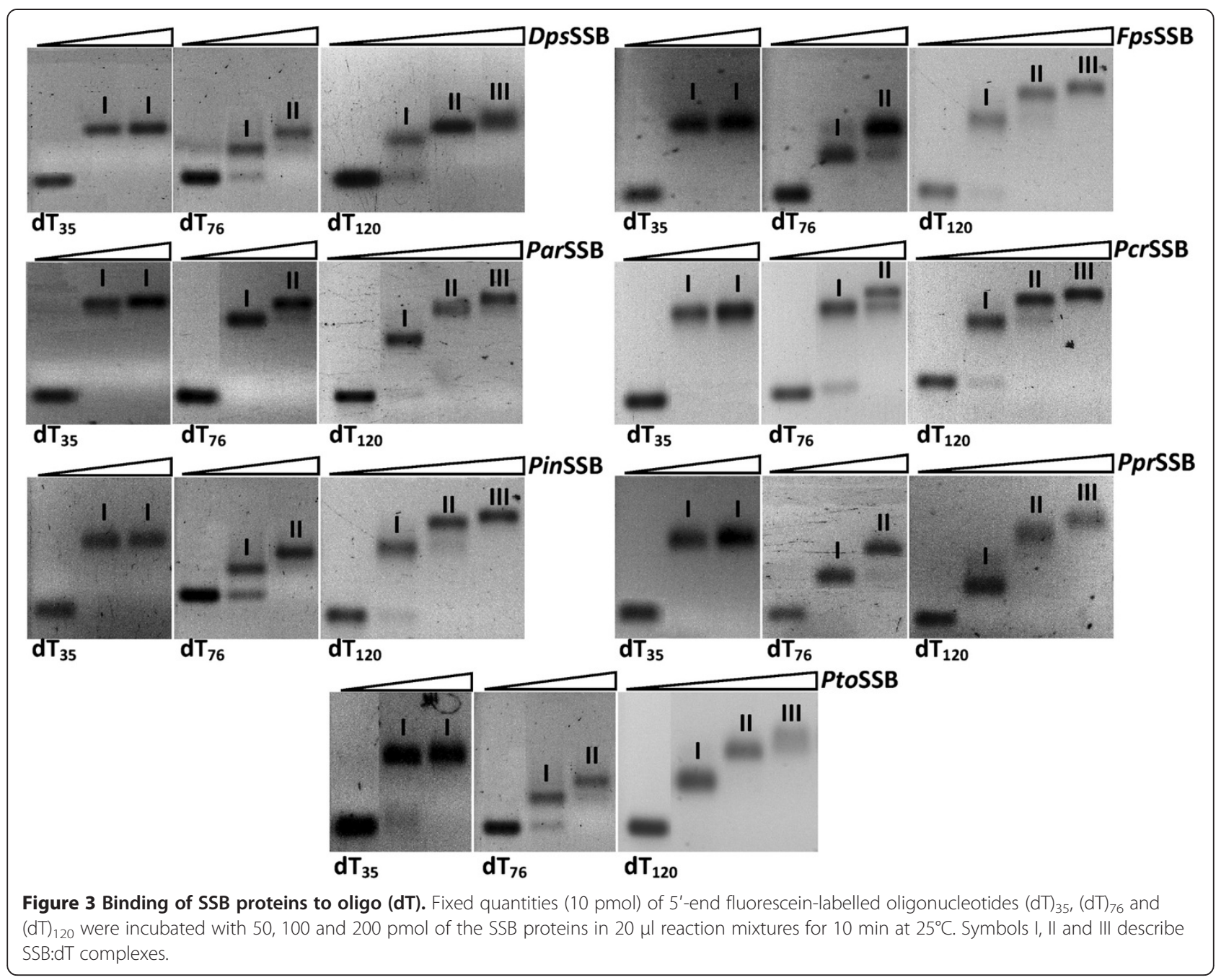

In order to explore the binding properties of all the proteins in question further, we used fluorescence spectroscopy. All the bacterial SSBs which have been studied to date have shown a dramatic decrease of tryptophan fluorescence when binding to ssDNA. With an excitation wavelength of $295 \mathrm{~nm}$, the emission spectrum of SSB proteins at $25^{\circ} \mathrm{C}$ reached its maximum at $348 \mathrm{~nm}$, which is consistent with tryptophan fluorescence. On the addition of a saturating quantity of $(\mathrm{dT})_{76}$, the intrinsic fluorescence at $348 \mathrm{~nm}$ was quenched by $93 \pm 3 \%$ for the DpsSSB, FpsSSB, ParSSB, PcrSSB, and PtoSSB, by $90 \pm 3 \%$ for the PprSSB, and by $81 \pm 3 \%$ for the PinSSB. It was salt independent. The estimated binding site was determined as being approximately $30 \pm 2$ nucleotides long for the PinSSB, $31 \pm 2$ nucleotides for the DpsSSB and $32 \pm 2$ nucleotides for the ParSSB, PcrSSB, PprSSB, and PtoSSB. Practically no binding mode transition was observed when changing the ionic strength from low to high salt (Figure 4). However, for the FpsSSB, a binding- mode transition of $31 \pm 2$ nucleotides at low salt concentrations and $45 \pm 2$ at high ones was observed.

\section{dsDNA melting point destabilization}

A destabilization of DNA double strands in the presence of SSB must be expected as a thermodynamic consequence of SSB proteins binding specifically to ssDNA and not to dsDNA. The results of duplex DNA (44 bp) destabilization by the DpsSSB, FpsSSB, ParSSB, PcrSSB, PinSSB, PprSSB, PtoSSB, and EcoSSB are shown in Figure 5. The melting temperature of dsDNA in $0.1 \mathrm{M}$ $\mathrm{NaCl}$ is decreased from 75 to $70^{\circ} \mathrm{C}$ by the DpsSSB, from 75 to $69^{\circ} \mathrm{C}$ by the FpsSSB and PinSSB, from 75 to $67^{\circ} \mathrm{C}$ by the ParSSB, from 75 to $65^{\circ} \mathrm{C}$ by the PprSSB, from 75 to $64^{\circ} \mathrm{C}$ by the PcrSSB, and from 75 to $58^{\circ} \mathrm{C}$ by the PtoSSB. In comparison, the melting temperature of the dsDNA is decreased from 75 to $62^{\circ} \mathrm{C}$ by the EcoSSB under the same conditions. The experiments were 

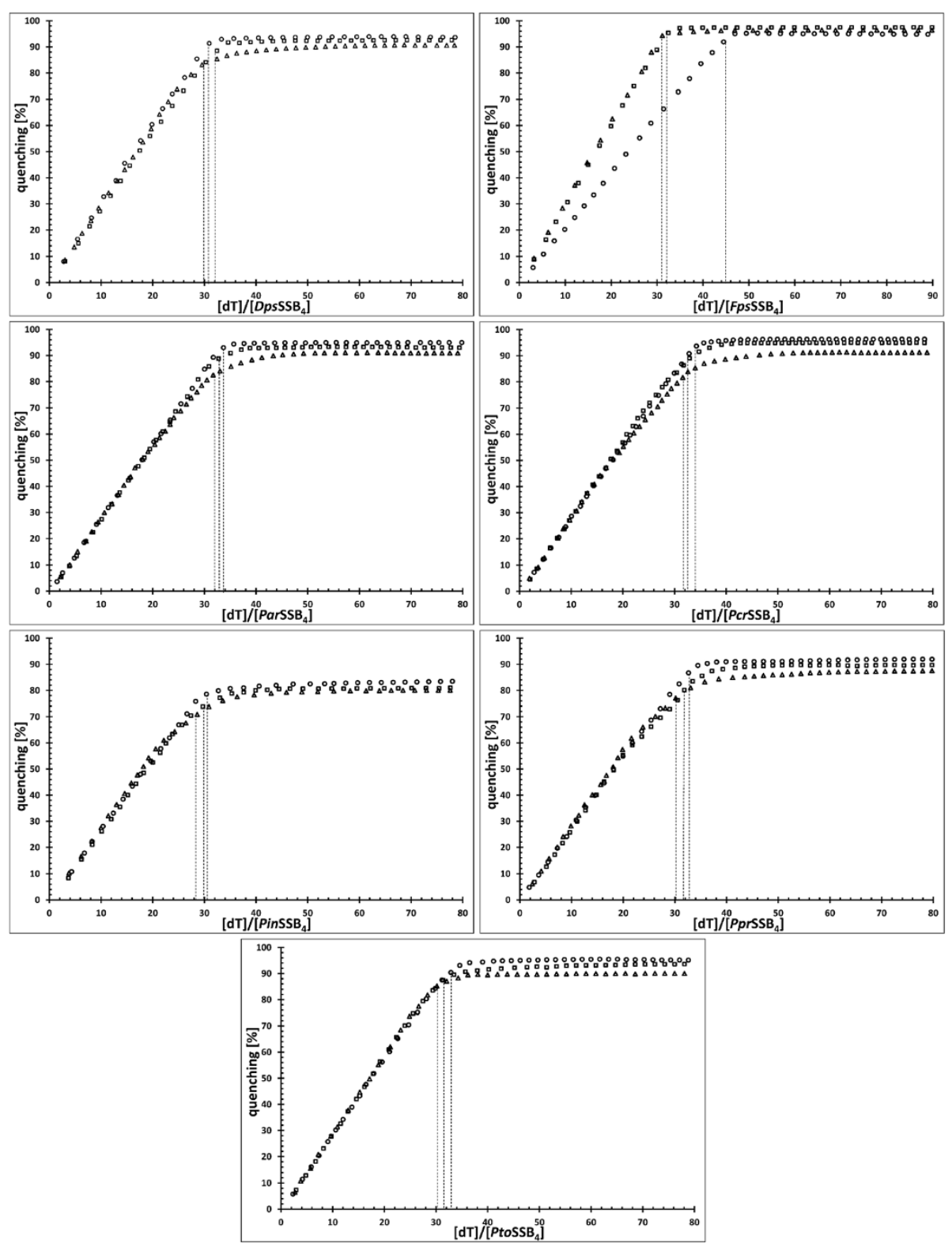

Figure 4 Inverse fluorescence titration of SSB proteins with oligo(dT) ${ }_{76}$. The $1.5 \mathrm{nmol}$ samples of the SSB proteins under study were titrated with $(\mathrm{dT})_{76}$ at $2 \mathrm{mM}(\Delta), 100 \mathrm{mM}(\square)$ and $300 \mathrm{mM}(\mathrm{o}) \mathrm{NaCl}$ binding buffer.

repeated three times with the same results on each occasion.

\section{Thermostability}

The results of the indirect thermostability experiments are shown in Figure 6. Although the proteins come from psychrophilic bacteria, they have a high thermostability. The half-lives of the ssDNA-binding activities of the SSBs at $100^{\circ} \mathrm{C}$ and $95^{\circ} \mathrm{C}$ are $5 \mathrm{~min}$ for the DpsSSB, FpsSSB and PtoSSB, and $15 \mathrm{~min}$ for the PinSSB. The thermostability of the ParSSB and PprSSB was 15 min at $100^{\circ} \mathrm{C}$ and $30 \mathrm{~min}$ at $95^{\circ} \mathrm{C}$, while for the PcrSSB, the half-lives were 30 and $45 \mathrm{~min}$ at those temperatures. The DpsSSB, FpsSSB and PinSSB proteins share halflives of $15 \mathrm{~min}$ at $90^{\circ} \mathrm{C}$ and $30 \mathrm{~min}$ at $85^{\circ} \mathrm{C}$. A $50 \%$ loss of ssDNA-binding activity at $90^{\circ} \mathrm{C}$ was observed for the PtoSSB after $10 \mathrm{~min}$ of incubation, for the ParSSB and PprSSB after $45 \mathrm{~min}$, and for the PcrSSB after $60 \mathrm{~min}$. The thermostability of the $P$. torquis SSB was $15 \mathrm{~min}$ at $85^{\circ} \mathrm{C}$ and $80^{\circ} \mathrm{C}, 30 \mathrm{~min}$ at $70^{\circ} \mathrm{C}$, and $45 \mathrm{~min}$ at $65^{\circ} \mathrm{C}$. There is a $50 \%$ decline in the activity of the ParSSB and PprSSB after $60 \mathrm{~min}$ at a temperature of $85^{\circ} \mathrm{C}$ and in that the DpsSSB, FpsSSB and PinSSB after 30, 45 and 60 min at $80^{\circ} \mathrm{C}$, respectively. A half-life of $60 \mathrm{~min}$ was 


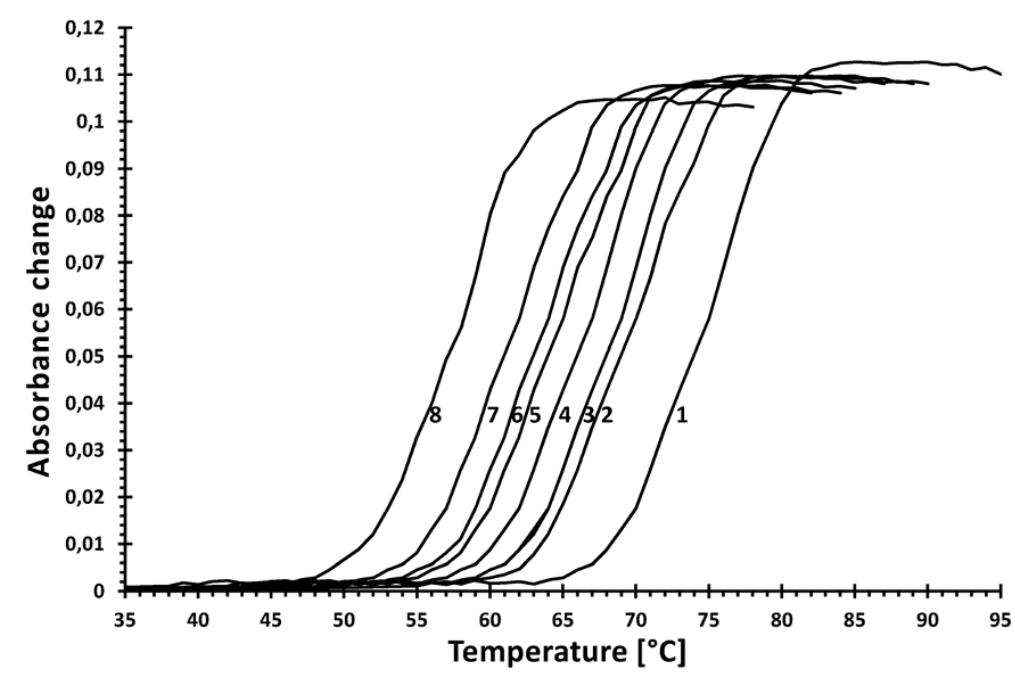

Figure 5 Melting profiles of dsDNA and its complexes with SSB proteins. A 0.67 nmol sample of duplex DNA (44 bp) was incubated alone (1) and with $4 \mathrm{nmol}$ of the DpsSSB (2), FpsSSB and PinSSB (3), ParSSB (4), PprSSB(5), PcrSSB (6), EcoSSB (7) and PtoSSB (8), in a standard buffer containing $0.1 \mathrm{NaCl}$. Absorbance changes were measured at $260 \mathrm{~nm}$.

observed for the FpsSSB at $75^{\circ} \mathrm{C}$ and for the DpsSSB and PtoSSB at $60^{\circ} \mathrm{C}$. In comparison, under the same conditions, the activity of the EcoSSB decreased by $50 \%$ after $15 \mathrm{~min}$ at $100^{\circ} \mathrm{C}, 30 \mathrm{~min}$ at $95^{\circ} \mathrm{C}, 45 \mathrm{~min}$ at $90^{\circ} \mathrm{C}$, and 60 min at $85^{\circ} \mathrm{C}$.

When analyzed by differential scanning microcalorimetry (DSC), the thermal unfolding was found to be an irreversible process in the PcrSSB, PinSSB and PprSSB, and partially reversible for the DpsSSB, FpsSSB, ParSSB and PtoSSB, as can be seen in the rescan thermograms (Figure 7). At melting temperatures $\left(\mathrm{T}_{\mathrm{m}}\right)$ of $59.9^{\circ} \mathrm{C}, 63^{\circ} \mathrm{C}$, $57.9^{\circ} \mathrm{C}, 59.5^{\circ} \mathrm{C}$, and $58.7^{\circ} \mathrm{C}$, respectively, the ParSSB, PcrSSB, PinSSB, PprSSB, and PtoSSB had a lower thermostability than the EcoSSB which had a $\mathrm{T}_{\mathrm{m}}$ of $69.0^{\circ} \mathrm{C}$. The DpsSSB and FpsSSB, with $\mathrm{T}_{\mathrm{m}}$ of $78.5^{\circ} \mathrm{C}$ and $69.4^{\circ} \mathrm{C}$, demonstrated more thermostablity than the EcoSSB, but still had less thermostable than the TmaSSB, at a $\mathrm{T}_{\mathrm{m}} 109.3^{\circ} \mathrm{C}$ [28]. The thermograms of these SSB proteins showed no characteristic signs of heavily aggregated proteins after heat denaturation. Although the proteins under study come from psychrophilic microorganisms, they have a relatively high thermostability.

\section{Discussion}

In this report, we have described the purification and characterization of single-strand DNA-binding proteins from obligate psychrophilic bacteria $D$. psychrophila, $P$. ingrahamii, $P$. profundum and $P$. torquis and the facultative psychrophilic bacteria $F$. psychrophilum, $P$. arcticus and $P$. cryohalolentis. All the proteins investigated form tetramers in solution, as demonstrated by three methods: chemical cross-linking experiments, sedimentation analysis and gel filtration chromatography. The results of the sequence analysis verified that an ssDNA binding domain in one monomer of each protein possesses a canonical oligonucleotide binding fold (OB-fold) very similar to that observed in the structure of the E. coli SSB. The OB-fold in the proteins in question demonstrated a high level of identity and similarity to EcoSSB, with DpsSSB at 55\% and $75 \%$, FpsSSB at $38 \%$ and $52 \%$, ParSSB at $57 \%$ and $73 \%$, PcrSSB at $58 \%$ and $74 \%$, PinSSB at $61 \%$ and $82 \%, P p r S S B$ at $82 \%$ and $90 \%$, and PtoSSB at $42 \%$ and $62 \%$, which was somewhat surprising, given that they come from taxonomical distant microorganisms living in different environments. They show a high differential in both the molecular mass of their monomers and the length of their amino acid sequences. Of the known SSBs with one OB-fold, the DpsSSB is the smallest and the FpsSSB is the shortest.

The ParSSB, PcrSSB, PinSSB, PprSSB and PtoSSB have melting temperatures $\left(\mathrm{T}_{\mathrm{m}}\right)$ of $59.9^{\circ} \mathrm{C}, 63^{\circ} \mathrm{C}, 57.9^{\circ} \mathrm{C}, 59.5^{\circ}$ $\mathrm{C}$ and $58.7^{\circ} \mathrm{C}$, respectively, which are somewhat lower than for the EcoSSB, at $69.0^{\circ} \mathrm{C}$. With $\mathrm{T}_{\mathrm{m}}$ of $78.5^{\circ} \mathrm{C}$ and $69.4^{\circ} \mathrm{C}$, the DpsSSB and FpsSSB are more thermostable than the EcoSSB, but their thermostability is not at the level of that for the thermophilic TmaSSB, with a $\mathrm{T}_{\mathrm{m}}$ $109.3^{\circ} \mathrm{C}$, or even for the TaqSSB, with $\mathrm{T}_{\mathrm{m}}$ of $86.8^{\circ} \mathrm{C}$ [28]. The indirect thermal stability tests showed that both mesophilic and psychrophilic SSBs retain their binding activity at temperatures higher than their melting temperature for specified incubation times. These proteins could thus be used in molecular biology in high-temperature reactions such as nucleic acid amplification.

It is well known that cold-adapted proteins exhibit greater flexibility than their mesophilic counterparts, with a reduced number of weak interactions. This flexibility is 

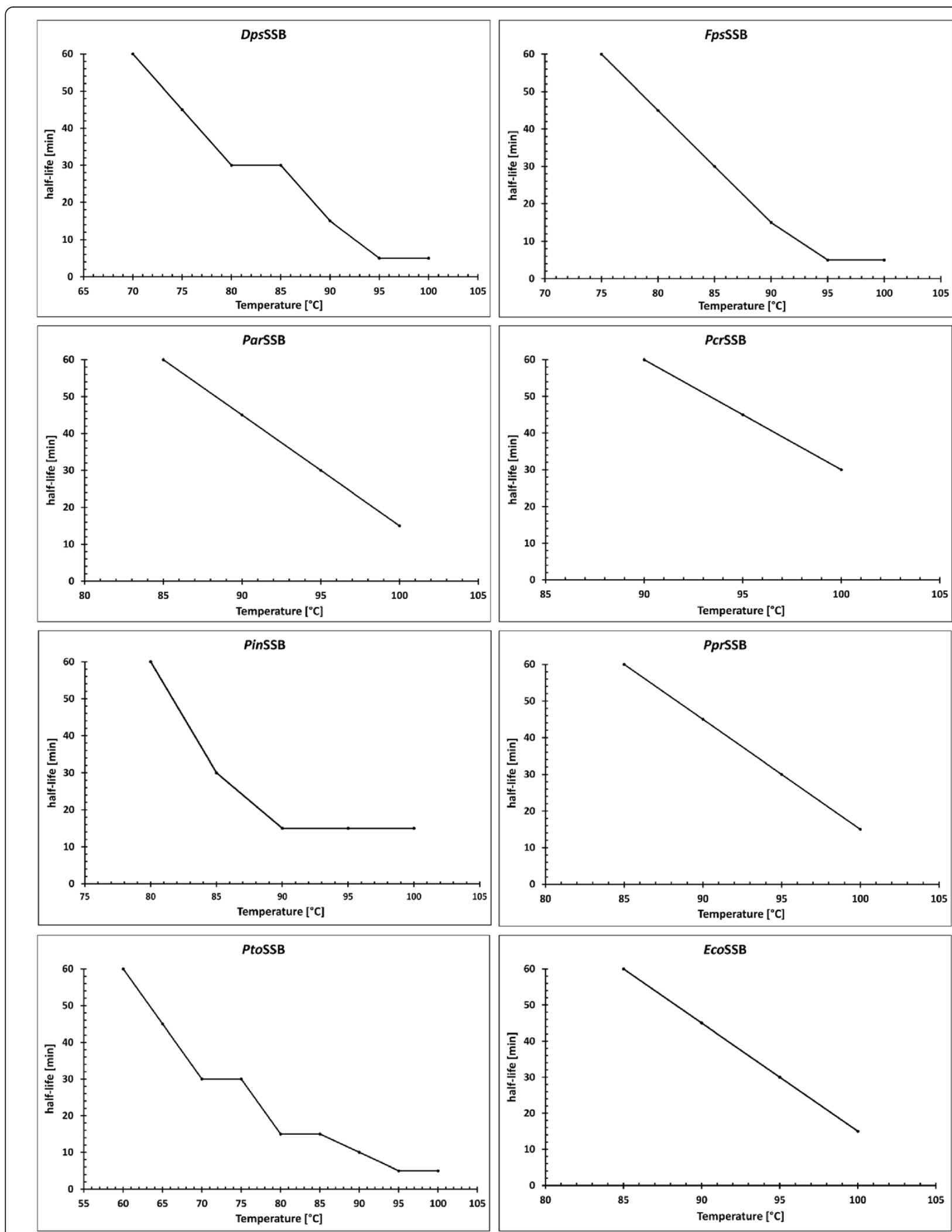

Figure 6 (See legend on next page.) 
(See figure on previous page.)

Figure 6 The half-lives of the SSB proteins. A fixed quantity of each SSB protein was incubated at temperatures ranging from $60^{\circ} \mathrm{C}$ to $100^{\circ} \mathrm{C}$ for $0,1,2.5,5,10,15,30,45$, and 60 min. 0.05 pmol 5'-end fluorescein-labelled oligonucleotide (dT) 35 was then added. The protein-DNA complexes were separated from the free DNA by $2 \%$ agarose gel electrophoresis. The incubation periods for each temperature, where $50 \%$ of ( $\mathrm{dT}$ ) $35 \mathrm{Was}$ bound, were noted.

often associated with the reduced stability of the psychrophilic protein. In comparison to their mesophilic equivalents, these proteins also often feature a higher Gly content; a lower basic amino acid content, particularly Arg, with a decreased Arg/(Arg + Lys)ratio; a lower Pro content, resulting from Pro deletion or substitution by other small residues such as Ala, for example; fewer hydrogen bonds and aromatic interactions; and residues which are more polar, and less hydrophobic, resulting in the destabilization of the hydrophobic core. All these characteristics work together to increase the number of degrees of conformational freedom by introducing flexible residues on the protein surface and destabilizing the protein core by weakening the intermolecular forces. In this context, the DpsSSB,
FpsSSB, ParSSB, PcrSSB, PinSSB, PprSSB, and PtoSSB proteins have some cold adaptation qualities.

With the exception of the PcrSSB and PprSSB, the proteins under study have a charged residues content of Asp, Glu, Lys, His and Arg, with DpsSSB at 24.5\%, FpsSSB at 29.3\%, ParSSB at 20.1\%, PcrSSB at $18.3 \%$, PinSSB at $21.2 \%$, PprSSB at $18.0 \%$, and PtoSSB at $30.4 \%$ ) which is higher than the SSB from E. coli, at $19.7 \%$ (Table 3). Furthermore, the FpsSSB and PtoSSB share a charged amino acid residues content which is close to that of the TteSSB3, at $30.7 \%$. In the thermophilic proteins, these residues may be involved in the ionic networks stabilization of the interdomain surface. In the DpsSSB, FpsSSB, ParSSB, PcrSSB, PinSSB, PprSSB and
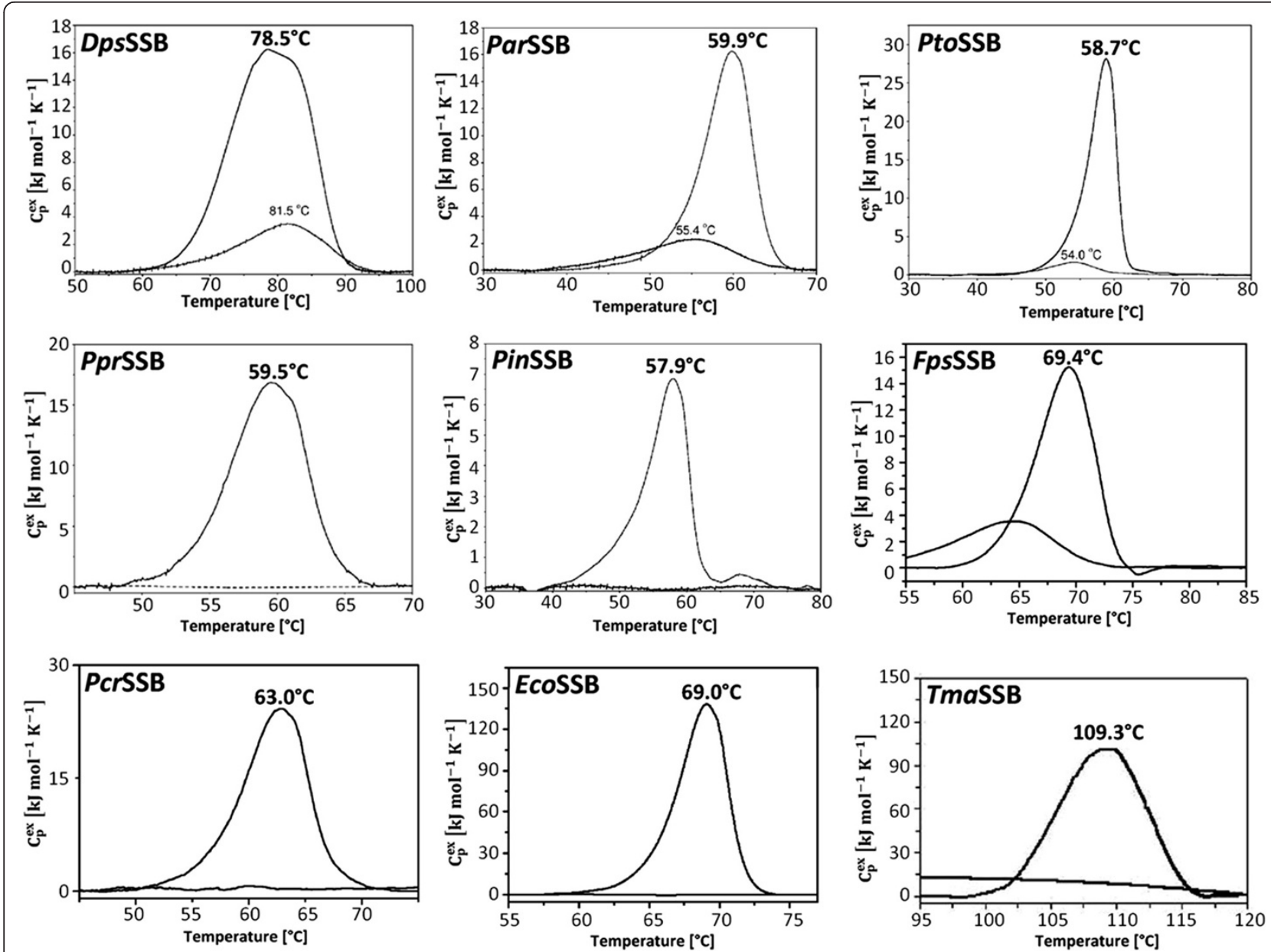

Figure 7 DSC thermograms of SSB proteins. Samples containing $2 \mathrm{mg} / \mathrm{ml}$ of the DpsSSB, ParSSB, PtoSSB, PprSSB, PinSSB, FpsSSB, PcrSSB, ECOSSB, and TmaSSB were analyzed in $50 \mathrm{mM}$ of potassium phosphate buffer pH 7.5 and $150 \mathrm{mM} \mathrm{NaCl}$. The melting temperatures are shown. 
PtoSSB, the content of Arg residues and the Arg/(Arg + Lys) ratio are $7.0 \%$ and $0.63,2.9 \%$ and $0.22,4.7 \%$ and $0.53,4.6 \%$ and $0.55,4.5 \%$ and $0.43,4.4 \%$ and 0.54 , and $2.6 \%$ and 0.20 , respectively. These factors are definitely lower in the psychrophilic SSBs than in their mesophilic $E$. coli equivalent, at $5.6 \%$ and 0.62 , with the exception of DpsSSB, and the thermophilic SSBs TteSSB3, at 6.0\% and 0.53 , and TmaSSB, at $10.6 \%$ and 0.75 ). This feature has been considered as a hallmark of psychrozymes [29-35]. The ability to form multiple salt bridges with acidic Asp and/or Glu amino acid residues and hydrogen bonds with other amino acids is normal for arginine. The decrease of Arg content, even the conservative replacement of Arg with Lys, entails a reduction in the number of salt bridges.

The glycine content in psychrophilic SSBs, particularly in the DpsSSB, at $11.3 \%, \operatorname{ParSSB}$, at $16.4 \%, \operatorname{PcrSSB}$, at $16.9 \%$, and PprSSB, at 10.4\%, and in the mesophilic EcoSSB, at $16.3 \%$, is much higher than in the thermophilic SSBs, at $6.0 \%$ and $4.3 \%$ for TteSSB3 and TmaSSB, respectively. This accords with the known tendency of thermostable proteins to have a preference for a decrease in the Gly content in positions of low structural importance for fold conservation [36,37].

The high content of glutamine and asparagine residues observed in the ParSSB, at 20.0\%, PcrSSB, at 23.0\%, PinSSB, at 24.93, and PprSSB, at $25.4 \%$ is one and a half times greater than that of the EcoSSB, at $14.5 \%$ and much higher than for the thermophilic SSBs, at 5.3\% and $2.8 \%$ for the TteSSB3 and TmaSSB, respectively. Of the 39 glutamine residues in the PinSSB and PprSSB, 34 are located in the C-terminal fragment of the former and 29 in that of the latter, which represents, respectively, $30.4 \%$ and $38.2 \%$ of that domain. At up to 9 rests side by side, the glutamine residue repetitions in the $\mathrm{C}$ terminal fragment of the PprSSB are extremely numerous, endowing the domain with a highly hydrophilic character. This area is reminiscent of the 'glutamine-rich
(Q-rich) regions' in proteins other than SSBs, which form a 'polar zipper' and with which different protein subunits interact in a specific manner.

The ratio of polar to non-polar amino acid residues is one of the major determinants of protein stability and increasing the fraction of polar and charged residues leads to protein disorder [29]. The content of polar amino acid residues $\mathrm{N}, \mathrm{Q}, \mathrm{S}, \mathrm{T}$, and $\mathrm{Y}$ in the DpsSSB, FpsSSB, ParSSB, PcrSSB, PinSSB, PprSSB, and PtoSSB is $30.2 \%, 31.5 \%, 33.3 \%, 37.4 \%, 36.5 \%, 36.0 \%$ and $25.8 \%$, respectively. With the exception of PtoSSB, this is considerably more than that found in the mesophilic EcoSSB, at $27.4 \%$, and very much more than that found in the thermophilic SSBs, at $21.3 \%$ and $19.8 \%$ for TteSSB3 and TmaSSB, accordingly. Russell [35] and Zuber [38] noticed that psychrophilic proteins appear to have more polar residues than thermophiles or mesophiles do, which is consistent with our research. As mentioned previously, a lower Pro content is one of the features of cold-adapted proteins. In the proteins under study, only the DpsSSB, at 4.2\%, FpsSSB, at 2.1\%, ParSSB, at 4.7\%, and PcrSSB, at $4.6 \%$, possess a lower proline content than their mesophilic and thermophilic counterparts, with EcoSSB, at 6.7\%, TteSSB3, at 6.0\% and TmaSSB, at 7.1\%.

Tiny and small amino acids were observed to be significantly increased in the beta sheets and loops of the psychrophilic proteins as compared with their mesophilic counterparts [39]. Their compositions in the SSBs in question are less than in the EcoSSB, at $61.0 \%$. Moreover, the FpsSSB and PinSSB have a lower content of these residues, at 54\%, than the TteSSB3, at 56\%. The composition of the small and tiny residues in the PprSSB, at 50\%, and the PtoSSB, at 52\%, is even less than in the TmaSSB, at 53\%.

Aromatic amino acid residues are known to play an important role in stabilizing the three-dimensional structure of proteins. Psychrophilic proteins usually display a decrease in these amino acids. The psychrophilic SSBs deviate from this rule; all of proteins investigated show a

Table 3 Percentage amino acid content of the SSB proteins under comparison

\begin{tabular}{lcccccccccccccccccccc}
\hline SSB & Ala & Ile & Leu & Val & Met & Gly & Pro & Lys & Arg & Asp & Glu & Gln & Asn & Ser & Thr & His & Trp & Phe & Tyr & Cys \\
\hline DpsSSB & 7.0 & 6.3 & 4.9 & 3.5 & 2.8 & 11.3 & 4.2 & 4.2 & 7.0 & 4.9 & 7.7 & 4.9 & 6.3 & 9.2 & 7.0 & 0.7 & 2.8 & 1.4 & 2.8 & 0.7 \\
FpsSSB & 4.3 & 7.9 & 5.0 & 6.4 & 2.1 & 6.4 & 2.1 & 10.0 & 2.9 & 5.0 & 9.3 & 2.1 & 7.1 & 8.0 & 10.7 & 2.1 & 1.4 & 4.3 & 3.6 & 1.4 \\
ParSSB & 8.0 & 5.2 & 3.3 & 2.8 & 1.9 & 16.4 & 4.7 & 4.2 & 4.7 & 5.6 & 4.2 & 12.2 & 8.0 & 5.6 & 4.2 & 1.4 & 0.9 & 3.3 & 3.3 & 0 \\
PcrSSB & 6.8 & 4.6 & 2.7 & 2.7 & 1.8 & 16.9 & 4.6 & 3.7 & 4.6 & 5.0 & 4.1 & 12.8 & 10.0 & 7.3 & 4.1 & 0.9 & 0.9 & 3.2 & 3.2 & 0 \\
PinSSB & 7.7 & 1.8 & 3.6 & 4.5 & 3.6 & 6.8 & 9.9 & 5.9 & 4.5 & 4.5 & 5.4 & 17.6 & 6.3 & 3.6 & 6.3 & 0.9 & 1.8 & 2.3 & 2.7 & 0.5 \\
PprSSB & 7.7 & 3.3 & 3.8 & 6.6 & 2.7 & 10.4 & 7.1 & 3.8 & 4.4 & 3.8 & 5.5 & 21.3 & 4.4 & 3.8 & 3.8 & 0.5 & 2.2 & 2.2 & 2.7 & 0 \\
PtoSSB & 5.3 & 5.3 & 4.6 & 6.0 & 2.6 & 6.0 & 7.3 & 10.6 & 2.6 & 5.3 & 9.9 & 5.3 & 4.6 & 3.3 & 9.3 & 2.0 & 1.3 & 3.3 & 3.3 & 2.0 \\
EcoSSB & 7.3 & 2.8 & 4.5 & 7.3 & 3.4 & 16.3 & 6.7 & 3.4 & 5.6 & 4.5 & 5.6 & 10.1 & 4.5 & 5.6 & 5.0 & 0.6 & 2.2 & 2.2 & 2.2 & 0 \\
TteSSB3 & 4.0 & 5.3 & 7.3 & 8.7 & 2.0 & 6.0 & 6.0 & 5.3 & 6.0 & 10.7 & 8.0 & 1.3 & 4.0 & 6.7 & 8.0 & 0.7 & 2.0 & 6.0 & 1.3 & 0 \\
TmaSSB & 5.0 & 4.3 & 5.7 & 9.2 & 2.8 & 4.3 & 7.1 & 3.5 & 10.6 & 6.4 & 12.8 & 0.7 & 2.1 & 5.0 & 10.6 & 0 & 0.7 & 7.8 & 1.4 & 0 \\
\hline
\end{tabular}


higher content of these residues than the EcoSSB, at 6.6\%. The FpsSSB has the same number of aromatic amino acids in its sequence as the TteSSB3, namely $9.3 \%$.

It was also observed that, in psychrophilic proteins, the number of hydrophobic amino acids is lower than for their mesophilic counterparts. The content of hydrophobic amino acid residues in the DpsSSB, FpsSSB, ParSSB, PcrSSB, PinSSB, PprSSB, and PtoSSB is $44.2 \%, 39.9 \%, 46.5 \%, 44.2 \%, 42.0 \%, 46.0 \%$ and $41.7 \%$, respectively. The number of these residues in the psychrophilic SSB proteins is less than in the EcoSSB, at 52.7\%. Moreover, the aromatic residue content in the ParSSB and PprSSB is close to that of the TmaSSB, at $46.9 \%$.

Analysis of the amino acid sequence of the DpsSSB, FpsSSB, PinSSB and PtoSSB shows the presence of cystein residues to a number of $1,2,1$, and 3 , respectively. To date, these amino acid residues have not been found in any known SSBs. A residue such as proline or cystein has a significant impact on the stability and rigidity of the conformational structure of proteins. The presence of cystein residues in psychrophilic SSBs may affect their stability, particularly if disulphide bridges are formed.

Single strand DNA binding proteins have the property of causing the destabilization of duplex DNA and the same is true of the psychrophilic SSBs under study. The greatest decrease in dsDNA melting temperature was observed in the presence of the PtoSSB, at $17^{\circ} \mathrm{C}$, which was a more substantial change than in the presence of the EcoSSB, TaqSSB or TthSSB, at $13^{\circ} \mathrm{C}$ in each case [40-42].

Studies of other SSBs have often shown that the size of the binding site depends on the salt concentration. At least two distinctly different DNA-binding modes have been described for the EcoSSB, for example [3]. In high salt concentrations, 65 nucleotides bind per EcoSSB tetramer, with a fluorescence quench of almost $90 \%$ whereas, in low salt concentrations, 35 nucleotides are sufficient to saturate the protein and quench its fluorescence by only 53\%. Our current study has demonstrated that the binding site size of the DpsSSB, ParSSB, PcrSSB, PinSSB, PprSSB and PtoSSB has a constant value of approximately 30-32 nucleotides per tetramer, with one, salt-independent, DNA-binding mode. Binding-mode transition was only observed for the FpsSSB, at $31 \pm 2$ nucleotides at low salt concentrations and $45 \pm 2$ nucleotides at high ones. This is similar to the recently described psychrophilic PhaSSB, with 34 nucleotides per tetramer under low-salt conditions and 54-64 nucleotides at higher ones. This suggests that the FpsSSB and PhaSSB undergo a transition between ssDNA binding modes, something which is observed for the EcoSSB.

\section{Conclusion}

The results showed that SSB proteins from psychrophilic microorganisms are typical bacterial SSBs and possess relatively high thermostability, offering an attractive alternative to other thermostable SSBs in molecular biology applications.

\section{Methods}

Bacterial strains, plasmids, enzymes and reagents

D. psychrophila LSv54 (DSM 12343), P. arcticus 273-4 (DSM 17307), P. cryohalolentis K5 (DSM 17306) and $P$. ingrahamii 37 (DSM 17664) were purchased from The Leibniz Institute DSMZ (German Collection of Microorganisms and Cell Cultures, Germany). F. psychrophilum JIP02/86 (LMG 13180), P. profundum (LMG 19446) and P. torquis ATCC 700755 (LMG 21429) were purchased from BCCM/LMG (The Belgian Co-ordinated Collections of Micro-organisms, Belgium). Genomic sequences for those strains are available and were published: D. psychrophila (GenBank accession no. NC_006138; [16]), F. psychrophilum (GenBank accession no. NC_009613; [17]), P. arcticus (GenBank accession no. NC_007204; [18]), P. cryohalolentis (GenBank accession no. NC_007969; Gene Bank Project: PRJNA58373), P. ingrahamii (GenBank accession no. NC_008709; [19]), P. profundum (GenBank accession no. NC_006370; [20]) and P. torquis (GenBank accession no. NC_018721; [15]).

The E. coli TOP10 (Invitrogen, USA) was used for genetic constructions and gene expression. The $\mathrm{pBAD} / m y c-$ HisA plasmid (Invitrogen, USA) was used for constructing the expression system. The reagents for PCR were obtained from Blirt SA - DNA-Gdańsk (Poland). Specific primers, oligodeoxynucleotides and the oligonucleotides 5 '-endlabelled with fluorescein were purchased from Sigma (USA). The restriction enzymes were purchased from NEB (USA). EcoSSB, PhaSSB and TmaSSB were produced and purified in our laboratory according to published procedure $([7,28,43]$, respectively).

\section{Cloning of the ssb-like genes from psychrophilic bacteria} DNA from D. psychrophila, F. psychrophilum, P. arcticus, $P$. cryohalolentis, $P$. ingrahamii, $P$. profundum and $P$. torquis was isolated using an ExtractMe DNA Bacteria Kit (Blirt SA - DNA-Gdańsk, Poland). The specific primers for PCR amplification were designed and synthesized on the basis of the known $s s b$-like gene sequences. The forward (containing a NcoI recognition site) and reverse (containing a BglII or HindIII recognition site) primers are shown in Table 4. The boldface parts of primers sequences are complementary to the nucleotide sequences of the $s s b$ like genes, whereas $5^{\prime}$ overhanging ends of primers contain recognition sites for restriction endonucleases (underlined) and are designed to facilitate cloning. The PCR reaction solution $(25 \mu \mathrm{l})$ consisted of: $0.2 \mu \mathrm{g}$ of genomic DNA, $0.4 \mu \mathrm{M}$ 
of each primer, $1 \mathrm{mM}$ dNTPs, $2 \mathrm{mM} \mathrm{MgCl}$, $20 \mathrm{mM}$ Tris$\mathrm{HCl}, \mathrm{pH}$ 8.8, $50 \mathrm{mM} \mathrm{KCl,} 10 \mathrm{mM}\left(\mathrm{NH}_{4}\right)_{2} \mathrm{SO}_{4}, 0.1 \%$ Triton $\mathrm{X}-100$ and $2 \mathrm{U}$ Pwo DNA polymerase (Blirt SA DNAGdańsk, Poland). 35 cycles were performed, using the Veriti 96 Well Thermal Cycler (Applied Biosystems, USA), with a temperature profile of $1 \mathrm{~min}$ at $94^{\circ} \mathrm{C}, 1 \mathrm{~min}$ at $60^{\circ} \mathrm{C}$ and $1 \mathrm{~min}$ at $72^{\circ} \mathrm{C}$. The amplification products were analyzed by electrophoresis on $1 \%$ agarose gel stained with ethidium bromide, at a final concentration of $0.5 \mu \mathrm{g} / \mathrm{ml}$. Specific PCR products were obtained and purified using the ExtractMe Gel-Out Kit (Blirt SA DNA-Gdańsk, Poland). The PCR products were digested with NcoI and BglII or HindIII (NEB, USA), then purified, using the ExtractMe Clean-Up Kit (Blirt SA DNA-Gdańsk, Poland) and ligated into $\mathrm{pBAD} / m y c$-HisA plasmid (Invitrogen, USA) between the NcoI and BglII or NcoI and HindIII sites. The E. coli TOP10 cells were transformed with the ligation mixtures and transformants were examined for the presence of the $s s b$-like genes, using a gel retardation assay and restriction analysis. One clone was selected and sequenced to confirm the presence of the $s s b$ like genes. The appropriate pBADDpsSSB, pBADFpsSSB, pBADParSSB, pBADPcrSSB, pBADPinSSB, pBADPprSSB, and $\mathrm{pBADPtoSSB}$ recombinant plasmids were obtained.

\section{Expression and purification of SSBs}

The E. coli TOP10 strain transformed with pBADDpsSSB, pBADFpsSSB, pBADParSSB, pBADPcrSSB, pBADPinSSB, pBADPprSSB or pBADPtoSSB was grown at $30^{\circ} \mathrm{C}$ in Luria-Bertani medium, supplemented with $100 \mu \mathrm{g} / \mathrm{ml}$ of ampicillin, to an $\mathrm{OD}_{600}$ of 0.4 , and was induced by incubation in the presence of arabinose, at a final concentration of $0.02 \%$, for $20 \mathrm{~h}$. The cells were then harvested by centrifugation at 4,612 $\times g$ for $20 \mathrm{~min}$ and the pellets were resuspended in $50 \mathrm{ml}$ of buffer A $(20 \mathrm{mM}$ Tris- $\mathrm{HCl}$ $\mathrm{pH}$ 8.0, $50 \mathrm{mM} \mathrm{NaCl}, 1 \mathrm{mM}$ EDTA pH 8.0, 0.1\% Triton $\mathrm{X}-100$ ). The samples were sonicated eight times, for $30 \mathrm{~s}$ at $4^{\circ} \mathrm{C}$, and centrifuged at $10,000 \times g$ for $25 \mathrm{~min}$. The clarified supernatant was applied further directly onto QAEcellulose column (50 ml bed volume, EMD, USA) preequilibrated with 4 vol buffer B (20 mM Tris- $\mathrm{HCl}$ pH 8.0, 50 $\mathrm{mM} \mathrm{NaCl}, 1 \mathrm{mM}$ EDTA $\mathrm{pH}$ 8.0). Each of SSB proteins was eluted with linear gradient of $0.05-2 \mathrm{M} \mathrm{NaCl}$ in buffer B. The SSB-containing fractions were detected by SDSPAGE electrophoresis, after which, they were combined and loaded onto a ssDNA-cellulose column ( $5 \mathrm{ml}$, USB, USA) equilibrated with buffer $\mathrm{C}(20 \mathrm{mM}$ Tris- $\mathrm{HCl}$ pH 8.0, 0.25 M NaCl, 1 mM EDTA pH 8.0). SSB proteins were eluted with $1.5 \mathrm{M} \mathrm{NaCl}$ and $50 \%$ ethylene glycol. The elution fractions were dialyzed against $\mathrm{D}$ buffer (20 mM Tris- $\mathrm{HCl}$ pH 8.0, 0.15 M NaCl) and concentrated to $2 \mathrm{mg} / \mathrm{ml}$, using the Amicon Ultra-15 Filter Device MWCO 10000 (Millipore, USA). The purity of the SSBs was estimated using SDS-PAGE and the amounts were examined spectrophotometrically. The E. coli overexpression systems used in this study produced approximately $20 \mathrm{mg}$ of purified SSB proteins from $1 \mathrm{~L}$ of induced culture. The purity of the protein preparations was $95-98 \%$.

\section{Estimation of the native molecular mass}

The native molecular mass of examined SSBs was determined by three independent methods: (i) chemical cross-linking, (ii) sedimentation in glycerol gradient and (iii) analytical gel filtration.

Chemical cross-linking experiments were carried out using $0.5 \%(\mathrm{v} / \mathrm{v})$ glutaraldehyde for $15 \mathrm{~min}$, with SSBs

Table 4 The specific primers for PCR amplification

\begin{tabular}{|c|c|}
\hline Name & Primer sequence \\
\hline fpsssbNcol & 5' GGA GGA CCA TGG GGA ACG GAA CGT TAA ATA AAG TCA TG 3' \\
\hline fpsssbHindIII & 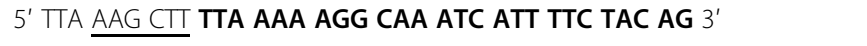 \\
\hline pcrssbNcol & 5' TTA CCA TGG GGC GCG GTG TTA ATA AAG TTA TCA TC 3' \\
\hline pcrssbHindIII & 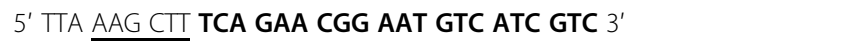 \\
\hline ptossbNcol & 5' GGA GGA CCA TGG CAG GAA CAC TCA ATA AAG TTA TGC $3^{\prime}$ \\
\hline ptossbHindlll & 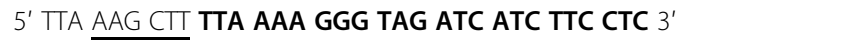 \\
\hline pprssbNcol & 5' GGA GGA CCA TGG CCA GTC GTG GTG TAA ATA AGG 3' \\
\hline pprssbBglll & 5' TTA AGA TCT CTA GAA TGG GAT ATC ATC ATC AAA ATC $3^{\prime}$ \\
\hline dpsssbNcol & $5^{\prime}$ TTA CCA TGG GGA TAA ATA AGG CAA TTT TAA TTG GTA ATC TAG $3^{\prime}$ \\
\hline dpsssbHindIII & 5' TTA $\underline{A A G ~ C \Pi T}$ CTA GAA GGG TAC GTC GTT AC 3' \\
\hline parssbNcol & 5' GGA GGA CCA TGG GGC GCG GTG TTA ATA AAG TTA TCA TC 3' \\
\hline parssbBglll & 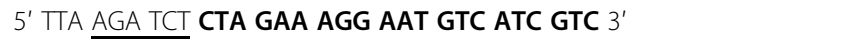 \\
\hline pinssbNcol & 5' TTA CCA TGG GGT TTA ACC GAA GCG TAA ACA AAG TAG 3' \\
\hline pinssbHindlll & 5' TTA AAG CTT CTA AAA AGG AAT ATC ATC ATC GAA ATC 3' \\
\hline
\end{tabular}

The boldface parts of the primers sequences are complementary to the nucleotide sequences of the ssb-like genes and the underlined parts are the recognition sites for restriction endonucleases. 
amount of 10 (ParSSB, PinSSB), 50 (DpsSSB, PcrSSB, PprSSB) or 100 (FpsSSB, PtoSSB) pmol, at $25^{\circ} \mathrm{C}$. The reaction was quenched by the addition of $1 \mathrm{M}$ Tris $-\mathrm{HCl}$ ( $\mathrm{pH}$ 8.0), and the cross-linked protein solutions were then analyzed using SDS-PAGE (12\%).

Linear 15 to $30 \%(\mathrm{w} / \mathrm{v})$ glycerol gradients, containing loading buffer (50 mM Tris- $\mathrm{HCl}, \mathrm{pH} 7.5,0.5 \mathrm{M} \mathrm{NaCl}, 1$ $\mathrm{mM}$ EDTA and $5 \mathrm{mM} \beta$-mercaptoethanol) were prepared in $5 \mathrm{ml}$ Beckman centrifuge tubes. Standard proteins were: carbonic anhydrase (29 kDa), bovine albumin (66 kDa), alcohol dehydrogenase $(150 \mathrm{kDa})$ and $\beta$-amylase $(200 \mathrm{kDa})$ taken from Sigma Gel Filtration Markers Kit (Cat no. MWGF1000). $50 \mu \mathrm{l}$ of a $300 \mu \mathrm{M}$ DpsSSB, FpsSSB, ParSSB, PcrSSB, PinSSB, PprSSB and PtoSSB proteins in loading buffer, and the corresponding amounts of EcoSSB, PhaSSB and standard proteins, were layered over $3.5 \mathrm{ml}$ of the glycerol gradient and were centrifuged in individual tubes. The gradients were centrifuged at $4^{\circ} \mathrm{C}$ in a Beckman SW 60 rotor at $46,000 \mathrm{rpm}$ for $24 \mathrm{~h}$; fractions were collected from the top. The proteins present in fractions were separated by SDS-PAGE.

Analytical gel filtration was carried out on a Superdex 200 HR75 10/300 GL column (Amersham Biosciences, USA), equilibrated with $20 \mathrm{mM}$ Tris- $\mathrm{HCl}$ pH 7.5, $150 \mathrm{mM}$ $\mathrm{NaCl}$ and $10 \mathrm{mM}$ EDTA. The samples were eluted with the same buffer at a flow rate of $0.5 \mathrm{ml} / \mathrm{min}$. The elution profile was monitored by recording the absorbance at $280 \mathrm{~nm}$. The molecular weight of SSB proteins were determined by comparing the elution patterns with those of standard proteins, taken from Gel Filtration Markers Kit (Sigma, USA), including $\beta$-amylase $(200 \mathrm{kDa})$, alcohol dehydrogenase $(150 \mathrm{kDa})$, bovine albumin $(66 \mathrm{kDa})$ and carbonic anhydrase $(29 \mathrm{kDa})$.

\section{Agarose gel electrophoresis mobility shift assays (EMSA)}

A fixed quantity $(10 \mathrm{pmol})$ of $5^{\prime}$-end fluoresceinlabelled oligonucleotides $(\mathrm{dT})_{35},(\mathrm{dT})_{76}$ and $(\mathrm{dT})_{120}$ were incubated with 50, 100 and 200 pmol of examined SSB proteins for $10 \mathrm{~min}$ at $25^{\circ} \mathrm{C}$ in a binding buffer (20 mM Tris- $\mathrm{HCl} \mathrm{pH} \mathrm{8.0,} 100 \mathrm{mM} \mathrm{NaCl}$ and $1 \mathrm{mM}$ EDTA) to a final reaction volume of $20 \mu \mathrm{l}$. Subsequently the reaction products with oligos were loaded onto $2 \%$ agarose gel without ethidium bromide and separated by electrophoresis in a TAE buffer (40 mM Tris acetate $\mathrm{pH} 7.5$ and $1 \mathrm{mM}$ EDTA). The bands corresponding to the unbound ssDNA and various SSB-ssDNA complexes were visualized under UV light and photographed.

\section{Fluorescence titration}

Fluorescence titrations were carried out in a Perkin-Elmer LS-5B luminescence spectrometer as described earlier [44]. The binding reactions were assembled in $2 \mathrm{ml}$ buffer of $20 \mathrm{mM}$ Tris- $\mathrm{HCl} \mathrm{pH}$ 8.0, $1 \mathrm{mM}$ EDTA containing 2
$\mathrm{mM}, 100 \mathrm{mM}$ or $300 \mathrm{mM} \mathrm{NaCl}$ and incubated at $25^{\circ} \mathrm{C}$. A fixed quantity $(1.5 \mathrm{nmol})$ of examined SSB proteins were incubated in the appropriate buffer at $25^{\circ} \mathrm{C}$ with increasing quantities of $(\mathrm{dT})_{76}$ oligonucleotide at excitation and emission wavelengths of 295 and $348 \mathrm{~nm}$, respectively. Binding curve analyses were carried out using Schwarz and Watanabe's model [45].

\section{Melting point destabilization of dsDNA}

Melting point curves were obtained by measuring the change in $\mathrm{A}_{260}$ in a Cary300Bio UV-Visible spectrophotometer (Varian) in $20 \mathrm{mM}$ sodium phosphate buffer $\mathrm{pH} 7.5$ containing $0.1 \mathrm{M} \mathrm{NaCl}$ and $1 \mathrm{mM}$ EDTA [46]. A mixture of $0.67 \mathrm{nmol} \mathrm{dsDNA}$ and $4 \mathrm{nmol}$ of particular SSB were gradually heated from $25^{\circ} \mathrm{C}$ to $95^{\circ} \mathrm{C}$ with heating rate of $1^{\circ} \mathrm{C} / \mathrm{min}$. The assay was performed using duplex DNA (44 bp) composed of two oligonucleotides: 5'-GAA CCG GAG GAA TGA TGA TGA TGA TGG TGC GGT TTG TCG GAC GG-3' and 5'-CCG TCC GAC AAA CCG CAC CAT CAT CAT CAT CAT TCC TCC GGT TC-3'.

\section{Thermostability}

The thermostability of the SSB proteins was determined by direct (DSC) and indirect methods.

Microcalorimetric measurements were performed using a NanoDSC microcalorimeter (Calorimetry Science Corporation, USA). Samples containing approximately $2.0 \mathrm{mg} / \mathrm{ml} \mathrm{SSB}$, in $50 \mathrm{mM}$ of potassium phosphate buffer $\mathrm{pH} 7.5$ and $150 \mathrm{mM} \mathrm{NaCl}$ were analyzed. The calorimetric scans were carried out between 0 and $100^{\circ} \mathrm{C}$, with a scan rate of $1^{\circ} \mathrm{C} / \mathrm{min}$. The reversibility of the transition was checked by cooling and reheating the same sample with the scan rate of $1^{\circ} \mathrm{C} / \mathrm{min}$. Results from the DSC measurements were analyzed with the NanoAnalyze Software V 1.1 (TA Instruments, USA).

The samples contained $0.75 \mu \mathrm{g}$ of FpsSSB, PprSSB and PtoSSB, $1 \mu \mathrm{g}$ of DpsSSB, ParSSB and PcrSSB, $1.5 \mu \mathrm{g}$ of EcoSSB and $3 \mu \mathrm{g}$ of PinSSB were incubated at temperatures ranging from $60^{\circ} \mathrm{C}$ to $100^{\circ} \mathrm{C}$ for $0,1,2.5,5$,

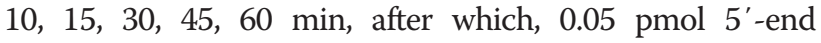
fluorescein-labelled oligonucleotide $(\mathrm{dT})_{35}$ was added. The samples were then loaded onto $2 \%$ agarose gels without ethidium bromide and separated by electrophoresis in a TAE buffer as described for EMSA tests. The incubation periods for each temperature, where $50 \%$ of $(\mathrm{dT})_{35}$ was bound, were noted.

\section{Protein sequence analysis}

The amino acid sequences of studied SSB proteins were analyzed using standard protein-protein BLAST and RPS-BLAST. Multiple sequence alignment was generated in ClustalX, using a PAM 500 scoring matrix. The 
results were prepared using the GeneDoc editor program (www.psc.edu/biomed/genedoc).

\author{
Abbreviations \\ dsDNA: Double-stranded DNA; OB fold: Oligonucleotide/oligosaccharide \\ binding fold; RPA: Replication protein A; SSB: Single-stranded DNA-binding; \\ ssDNA: Single-stranded DNA.
}

\section{Competing interests}

The authors declare that they have no conflict of interests.

\section{Authors' contributions}

MO conceived the study and carried out the molecular genetic studies. MN participated in the design of the study, carried out the molecular genetic studies and drafted the manuscript. JK participated in the design of study and drafted the manuscript. All the authors have read and approved the final manuscript.

\section{Acknowledgements}

This work was supported by Polish National Science Centre Grant NO. N/NZ1/01562 to M.N.

Received: 26 February 2014 Accepted: 31 March 2014

Published: 14 April 2014

\section{References}

1. Greipel J, Urbanke C, Maass G: The single-stranded DNA binding protein of Escherichia coli. Physicochemical properties and biological functions. In Protein-Nucleic Acid Interaction. Edited by Saenger W, Heinemann U. London: Macmillan; 1989:61-86.

2. Alani E, Tresher R, Griffith JD, Kolodner RD: Characterization of DNAbinding and strand-exchange stimulation properties of $\mathrm{y}-\mathrm{RPA}$, a yeast single-strand-DNA-binding protein. J Mol Biol 1992, 227:54-71.

3. Lohman TM, Overman LB: Two binding modes in Escherichia coli single strand binding protein-single stranded DNA complexes. Modulation by $\mathrm{NaCl}$ concentration. J Biol Chem 1985, 260:3594-3603.

4. Meyer RR, Laine PS: The single-stranded DNA-binding protein of Escherichia coli. Microbiol Rev 1990, 54:342-380.

5. Shereda RD, Kozlov AG, Lohman TM, Cox MM, Keck JL: SSB as an organizer/mobilizer of genome maintenance complexes. Crit Rev Biochem Mol 2009, 43:289-318.

6. Murzin AG: OB (oligonucleotide/oligosaccharide binding)-fold: common structural and functional solution for non-homologous sequences. EMBO J 1993, 2:861-867.

7. Olszewski M, Nowak M, Cyranka-Czaja A, Kur J: Identification and characterization of single-stranded DNA-binding protein from the facultative psychrophilic bacteria Pseudoalteromonas haloplanktis. Microbiol Res 2014, 169:139-147.

8. Nogi Y, Masui N, Kato C: Photobacterium profundum sp. nov., a new, moderately barophilic bacterial species isolated from a deep-sea sediment. Extremophiles 1998, 2:1-7.

9. Bartlett D, Wright M, Yayanos AA, Silverman M: Isolation of a gene regulated by hydrostatic pressure in a deep-sea bacterium. Nature 1989, 342:572-574.

10. Knoblauch C, Sahm K, Jorgensen BB: Psychrophilic sulfate-reducing bacteria isolated from permanently cold Arctic marine sediments description of Desulfofrigus oceanense gen. nov., sp. nov., Desulfofrigus fragile sp. nov., Desulfofaba gelida gen. nov., sp. nov., Desulfotalea psychrophila gen. nov., sp. nov. and Desulfotalea arctica sp. nov. Int I Syst Bacteriol 1999, 49:1631-1643.

11. Alvarez B, Secades P, McBride M, Guijarro J: Development of genetic techniques for the psychrotrophic fish pathogen Flavobacterium psychrophilum. Appl Envir Microb 2004, 70:581-587.

12. Bakermans C, Ayala-del-Rio HL, Ponder MA, Vishnivetskaya T, Gilichinsky D, Thomashow MF, Tiedje JM: Psychrobacter cryohalolentis sp. nov. and Psychrobacter arcticus sp. nov., isolated from Siberian permafrost. Int J Syst Evol Microbiol 2006, 56:1285-1291.

13. Bergholz PW, Bakermans C, Tiedje JM: Psychrobacter arcticus 273-4 Uses resource efficiency and molecular motion adaptations for subzero temperature growth. J Bacteriol 2009, 191:2340-2352.
14. Auman AJ, Breezee JL, Gosink JJ, Kämpfer P, Staley JT: Psychromonas ingrahamii sp. nov., a novel gas vacuolate, psychrophilic bacterium isolated from Arctic polar sea ice. Int J Syst Evol Microbiol 2006, 56:1001-1007.

15. Bowman JP, McCammon SA, Lewis T, Skerratt JH, Brown JL, Nichols DS, McMeekin TA: Psychroflexus torquis gen. nov., sp. nov., a psychrophilic species from Antarctic sea ice, and reclassification of Flavobacterium gondwanense (Dobson et al. 1993) as Psychroflexus gondwanense gen. nov., comb. nov. Microbiology 1998, 144:1601-1609.

16. Rabus R, Ruepp A, Frickey T, Rattei T, Fartmann B, Stark M, Bauer M, Zibat A, Lombardot T, Becker I, Amann J, Gellner K, Teeling H, Leuschner WD, Glockner F-O, Lupas AN, Amann R, Klenk H-P: The genome of Desulfotalea psychrophila, a sulfate-reducing bacterium from permanently cold Arctic sediments. Environ Microbiol 2004, 6:887-902.

17. Duchaud E, Boussaha M, Loux V, Bernardet JF, Michel C, Kerouault B, Mondot S, Bossy R, Caron C, Bessieres P, Gibrat JF, Dumetz F, Le Henaff M, Benmansour A: Complete genome sequence of the fish pathogen Flavobacterium psychrophilum. Nat Biotech 2007, 25:763-769.

18. Ayala-del-Rio HL, Chain PS, Grzymski JJ, Ponder MA, Ivanova N, Bergholz PW, Di Bartolo G, Hauser L, Land M, Bakermans C, Rodrigues D, Klappenbach J, Zarka D, Larimer F, Richardson P, Murray A, Thomashow M, Tiedje JM: The genome sequence of Psychrobacter arcticus 273-4, a psychroactive Siberian permafrost bacterium reveals mechanisms for adaptation to low temperature growth. Appl Environ Microbiol 2010, 76:2304-2312.

19. Riley M, Staley JT, Danchin A, Wang TZ, Brettin TS, Hauser LI, Land ML, Thompson LS: Genomics of an extreme psychrophile, Psychromonas ingrahamii. BMC Genomics 2008, 9:210.

20. Vezzi A, Campanaro S, D'Angelo M, Simonato F, Vitulo N, Lauro FM, Cestaro A, Malacrida G, Simionati B, Cannata N, Romualdi C, Bartlett DH, Valle G: Life at depth: Photobacterium profundum genome sequence and expression analysis. Science 2005, 307:1459-1461.

21. Lindner C, Nijland R, van Hartskamp M, Bron S, Hamoen LW, Kuipers OP: Differential expression of two paralogous genes of Bacillus subtilis encoding single-stranded DNA binding protein. J Bacteriol 2004, 186:1097-1105.

22. Makemson JC, Fulayfil NR, Landry W, Van Ert LM, Wimpee CF, Widder EA, Case JF: Shewanella woodyi sp. nov., an exclusively respiratory luminous bacterium isolated from the Alboran Sea. Int I Syst Bacterio/ 1997, 47:1034-1039.

23. Riley M, Abe T, Arnaud MB, Berlyn MK, Blattner FR, Chaudhuri RR, Glasner $J$ D, Horiuchi T, Keseler IM, Kosuge T, Mori H, Perna NT, Plunkett G 3rd, Rudd KE, Serres MH, Thomas GH, Thomson NR, Wishart D, Wanner BL: Escherichia coli K-12: a cooperatively developed annotation snapshot-2005. Nucleic Acids Res 2006, 34:1-9.

24. Barbe V, Cruveiller S, Kunst F, Lenoble P, Meurice G, Sekowska A, Vallenet D, Wang T, Moszer I, Médigue C, Danchin A: From a consortium sequence to a unified sequence: the Bacillus subtilis 168 reference genome a decade later. Microbiology 2009, 155:1758-1775.

25. Bao Q, Tian Y, Li W, Xu Z, Xuan Z, Hu S, Dong W, Yang J, Chen Y, Xue Y, Xu Y, Lai X, Huang L, Dong X, Ma Y, Ling L, Tan H, Chen R, Wang J, Yu J, Yang $\mathrm{H}$ : A complete sequence of the $T$. tengcongensis genome. Genome Res 2002, 12:689-700.

26. Nelson KE, Clayton RA, Gill SR, Gwinn ML, Dodson RJ, Haft DH, Hickey EK, Peterson JD, Nelson WC, Ketchum KA, MCDonald L, Utterback TR, Malek JA Linher KD, Garrett MM, Stewart AM, Cotton MD, Pratt MS, Phillips CA, Richardson D, Heidelberg J, Sutton GG, Fleischmann RD, Eisen JA, White O, Salzberg SL, Smith HO, Venter JC, Fraser CM: Evidence for lateral gene transfer between Archaea and bacteria from genome sequence of Thermotoga maritima. Nature 1999, 399:323-329.

27. Chilukuri LN, Bartlett DH: Isolation and characterization of the gene encoding single-stranded-DNA-binding protein (SSB) from four marine Shewanella strains that differ in their temperature and pressure optima for growth. Microbiology 1997, 143:1163-1174.

28. Olszewski M, Grot A, Wojciechowski M, Nowak M, Mickiewicz M, Kur J: Characterization of exceptionally thermostable single-stranded DNA-binding proteins from Thermotoga maritima and Thermotoga neapolitana. BMC Microbiology 2010, 10:260.

29. Feller G, Arpigny JL, Narinx E, Gerday C: Molecular adaptations of enzymes from psychrophilic organisms. Comp Biochem Phys A 1997, 118:495-499.

30. Feller G, Payan F, Theys F, Qian M, Haser R, Gerday C: Stability and structural analysis of alpha-amylase from the antarctic psychrophile Alteromonas haloplanctis A23. Eur J Biochem 1994, 222:441-447. 
31. Feller $G$, Thiry M, Gerday C: Nucleotide sequence of the lipase gene lip2 from the antarctic psychrotroph Moraxella TA144 and site-specific mutagenesis of the conserved serine and histidine residues. DNA Cell Biol 1991, 10:381-388.

32. Feller G, Gerday C: Psychrophilic enzymes: molecular basis of cold adaptation. Cell Mol Life Sci 1997, 53:830-841.

33. Van Petegem F, Collins T, Meuwis MA, Gerday C, Feller G, Van Beeumen J: The structure of a cold-adapted family 8 xylanase at 1.3 A resolution: structural adaptations to cold and investigation of the active site. $J$ Biol Chem 2003, 278:7531-7539.

34. Gerday C, Aittaleb M, Bentahir M, Chessa JP, Claverie P, Collins T, D'Amico S, Dumont J, Garsoux G, Georlette D, Hoyoux A, Lonhienne T, Meuwis MA, Feller G: Cold-adapted enzymes: from fundamentals to biotechnology. Trends Biotechnol 2000, 18:103-107.

35. Russell NJ: Toward a molecular understanding of cold activity of enzymes from psychrophiles. Extremophiles 2000, 4:83-90.

36. Matthews BW, Nicholson H, Becktel WJ: Enhanced protein thermostability from site-directed mutations that decrease the entropy of unfolding. Proc Natl Acad Sci USA 1987, 84:6663-6667.

37. Korolev S, Nayal M, Barnes WM, Di Cera E, Waksman G: Crystal structure of the large fragment of Thermus aquaticus DNA polymerase I at 2.5-A resolution: structural basis for thermostability. Proc Natl Acad Sci USA 1995, 92:9264-9268.

38. Zuber H: Temperature adaptation of lactate dehydrogenase. Structural, functional and genetic aspects. Biophys Chem 1988, 29:171-179.

39. Metpally RPR, Reddy BVB: Comparative proteome analysis of psychrophilic versus mesophilic bacterial species: Insights into the molecular basis of cold adaptation of proteins. BMC Genomics 2009, 10:11.

40. Williams KR, Murphy JB, Chase JW: Characterization of the structural and functional defect in the Escherichia coli single-stranded DNA binding protein encoded by the ssb-1 mutant gene. Expression of the ssb-1 gene under lambda pL regulation. J Biol Chem 1984, 259:11804-11811.

41. Genschel J, Litz L, Thole H, Roemling U, Urbanke C: Isolation, sequencing and overproduction of the single-stranded DNA binding protein from Pseudomonas aeruginosa PAO. Gene 1996, 182:137-143.

42. Dabrowski S, Olszewski M, Piatek R, Brillowska-Dabrowska A, Konopa G, Kur J: Identification and characterization of single-stranded-DNA-binding proteins from Thermus thermophilus and Thermus aquaticus - new arrangement of binding domains. Microbiology 2002, 148:3307-3315.

43. Dabrowski S, Kur J: Cloning, overexpression, and purification of the recombinant His-tagged SSB protein of Escherichia coli and use in polymerase chain reaction amplification. Protein Expr Purif 1999, 16:96-102.

44. Curth U, Greipel J, Urbanke C, Maass G: Multiple binding modes of the single-stranded DNA binding protein from Escherichia coli as detected by tryptophan fluorescence and site-directed mutagenesis. Biochemistry 1993, 32:2585-2591.

45. Schwarz G, Watanabe F: Thermodynamics and kinetics of co-operative protein-nucleic acid binding. I. General aspects of analysis of data. J Mol Biol 1983, 163:467-484

46. Augustyns K, Van Aerschot A, Van Schepdael A, Urbanke C, Herdewijn P. Influence of the incorporation of (S)-9-(3,4-dihydroxybutyl)adenine on the enzymatic stability and base-pairing properties of oligodeoxynucleotides. Nucleic Acids Res 1991, 19:2587-2593.

doi:10.1186/1471-2180-14-91

Cite this article as: Nowak et al.: Characterization of single-stranded DNA-binding proteins from the psychrophilic bacteria Desulfotalea psychrophila, Flavobacterium psychrophilum, Psychrobacter arcticus, Psychrobacter cryohalolentis, Psychromonas ingrahamii, Psychroflexus torquis, and Photobacterium profundum. BMC Microbiology 2014 14:91.

\section{Submit your next manuscript to BioMed Central and take full advantage of:}

- Convenient online submission

- Thorough peer review

- No space constraints or color figure charges

- Immediate publication on acceptance

- Inclusion in PubMed, CAS, Scopus and Google Scholar

- Research which is freely available for redistribution

Submit your manuscript at www.biomedcentral.com/submit
C Biomed Central 